\title{
On the acquisition of syllabic structure in Greek ${ }^{*}$
}

\author{
Ioanna Kappa \\ University of Crete
}

This study presents the results of an investigation into the acquisition of phonology of Greek by one child, between the ages $1 ; 10-2 ; 10$. Our claim is that these results are relevant to the study of prosodic structure, specifically to syllable structure. We provide evidence that at the early stage of acquisition the child has only the unmarked CV-syllables and that codas are acquired at a later stage in interaction with morphological development. We will also provide an example of constraints that are fully satisfied in child language becoming minimally violable later in development, that is development as constraint reranking.

Keywords: optimality, phonological development, acquisition, emergence of unmarked, syllabic structure

\section{Introduction}

This article constitutes the first part of an investigation into the acquisition of prosodic structure in Greek, specifically of syllable structure. We investigate the phonological development of early words and how the structure of the child's utterances gradually approaches the corresponding adult forms. We present a case study from a child's phonology, using longitudinal spontaneous production data of the child Sofia, from the age of $1 ; 10$ up to the age of 2;10. The data were collected weekly (recordings of 20-30 min. each, plus diary study).

The developmental patterns in acquisition data reveal that the child's phonology reflects properties of Universal Grammar. At the first stage, the child produces only unmarked CV-syllables. Sofia's phonology has no marked structures, specifically, no codas or complex onsets, e.g the proper name, Masc. Nom. Mápкос ['markos] is produced without codas as ['mako] by the age 2;2 
(Section 3.3). Sofia avoids onsetless syllables and uses a repair strategy for the few onsetless adult words that she selects, either by copying and filling in the empty onset of the syllable (cf. Fikkert 1994 for Dutch), or by reducing the onsetless syllable, e.g the adult form $\varepsilon \delta \omega$ [e'ðo] 'here' is realized as [de'do] [do] by the ages $1 ; 10 / 1 ; 10,7$ (Section 3.1). By means of these repair strategies, she reduces the markedness of her output. In case of forms beginning with complex onsets, she simplifies the clusters to a (less sonorous) single onset, e.g. the adult form $\pi \lambda \varepsilon \dot{\varepsilon} v \omega$ ['pleno] '(I) wash' is produced as ['peno] by the age 2;2 (Section 3.2) (cf. Kappa 1999). In recent works on Greek language acquisition (Kappa 1998b, to appear) it was shown that the child tries also to preserve the prosodic structure of the adult (target) forms. In case of disyllabic adult forms the child produces also disyllabic ones, i.e. she preserves the binary foot (тrochee in the case of Greek, cf. Malikouti-Drachman \& Drachman 1989). The multisyllabic adult forms are realised either as truncated disyllabic ones, e.g. the proper name, ғем.Nом Хрvбoúla [xri'sula] is produced as ['tula] by the age $2 ; 2$ or the child tries to preserve the number of syllables of the adult form, by means of reduplication, e.g. [tu'tula] (ages 2;3-2;9,7). We assume that the shape of the child's early words is constrained by principles of Universal Grammar, but varies according to the prosodic characteristics of word structure in the language being learned. The results of this investigation confirmed the above assumptions and provided evidence for the early construction of prosodic representations. The early words in Greek take the shape of prosodically well-formed units of the prosodic hierarchy and this phonetic shape is a bisyllabic maximum on word size, which applies at about age two, (cf. Kappa, 1998b). What is preserved in these words is rather the canonical left-headed foot, e.g. ['tula $]_{\mathrm{F}}$ in the above example, which constitutes a prosodically based minimal word, ${ }^{1}$ e.g. ['tula] $]_{\mathrm{PW}}$ (cf. Fee 1996 for English; Fikkert $1994^{2}$ for Dutch), and that the constraints invoked play a role in the stress system of Greek. In the case of reduplicated forms, like [tu'tula], the child preserves the unmarked trochaic foot, and the single, unfooted (reduplicated) syllable occurring at the left word edge is associated directly to the prosodic word, e.g. [tu ['tula $\left.]_{\min P W}\right]$. The role of the trochaic foot as the minimal word in Modern Greek has been also discussed in the study of Malikouti-Drachman (1999) on the formation of (adult) Greek hypocoristics. In this work it was shown that the base of hypocoristics is the full name and the output is formed by a foot template, mainly trochee, which is a minimal word and conforms to the prosodic pattern of the language. ${ }^{3}$ 


\subsection{Basics of Optimality Theory}

For the analysis of the data we adopt the framework of Optimality Theory (henceforth OT) as developed by Prince \& Smolensky (1993) and McCarthy \& Prince (1995). OT provides a unified model for child and adult phonology and the relation between the two and has offered a new view of generative phonology of how grammars yield surface representations from mental ones, which are referred as input and output representations, respectively. How the grammar yields the output representation from the input representation is crucially different in OT from that of derivational frameworks (Chomsky \& Halle 1968, and others). In the derivational frameworks the surface forms are derived from mental (underlying) representations through a series of rules that operate on different intermediate levels of representation. The rules apply in a serial fashion, i.e. each rule applies one at a time in a particular and fixed order. The rules and the order in which they apply constitute the grammar, along with underlying and surface representations. OT assumes a different organisation of grammar. In OT, instead of rules, there are constraints. All constraints are assumed to be innate, part of the Universal Grammar and grammars differ only in the relative ranking of these universal constraints. ${ }^{4}$ The relation between the input and the output representation is mediated by two entities in OT, defined as GeN (generator) and Eval (evaluator). GEN generates a potentially infinite number of possible output candidates, e.g. for the target word $\pi \omega \varsigma$ 'how', outputs would include forms similar to the input, such as [pos], [po], etc., as well as less similar forms such as [mo], [bo] etc. The Eval has to determine which of these candidates is most harmonic with the grammar. The Eval yields the output representation by considering a set of ranked constraints that determine what possible output form is most 'optimal' or 'harmonic', i.e. which possible output form best satisfies the constraints and their relative rankings. A particular constraint may be high ranked in one language, but low ranked in another. This allows for each language to have its own specific ranking, thereby permitting variation in the types of grammars that are observed. One crucial aspect of the OT framework is that constraints are violable, i.e. it is possible for a grammar to choose as optimal a candidate that does not satisfy every constraint. In a given language, certain constraints are more important than others, therefore they are ranked higher than other less important ones. Violations of those highly ranked constraints will be more serious than violations of less important (lower ranked) constraints. Moreover, each candidate is evaluated by all constraints at once in parallel, rather than in the serial fashion of derivational 
frameworks. The candidate that violates the fewest highly ranked constraints will be chosen as optimal by the grammar. The constraints are divided in three basic types: (a) the faithfulness constraints against deletion, epenthesis, feature changing. These constraints demand that the surface (output) forms resemble underlying (input) forms; (b) the markedness/wellformedness constraints, which require that output forms be unmarked in structure; ${ }^{5}$ (c) the alignment constraints, which relate to aligning phonological and morphological constituents with one another. Faithfulness and markedness constraints are antagonistic, i.e. faithfulness constraints may be violated in order to satisfy highly ranked markedness constraints or markedness constraints may be violated in order to satisfy highly ranked faithfulness constraints.

\subsection{Optimality Theory in phonological acquisition}

The framework of OT makes a specific proposal about the way in which the course of phonological acquisition proceeds. In particular, a child acquiring the phonology of his/her language must learn items of the lexicon and also the relative ranking of universal constraints as pertains to that language (Prince \& Smolensky 1993). It has long been observed that, at the earliest stages of phonological acquisition, a child's productions are 'simpler' than those of the adult in terms of featural, segmental and syllabic properties. Typically, a child's early productions are unmarked in structure (Jakobson 1968). Within OT, this unmarkedness translates into differences in constraint rankings between the child and adult grammars. Specifically, markedness constraints must be higher ranked in acquisition so that unmarked output forms are likely to surface in a child's speech. This claim is reflected by the predominant and accepted view that children's initial grammars consist of markedness constraints outranking faithfulness constraints $[\mathrm{M} » \mathrm{~F}]$, which is just the reverse pattern in fully developed systems (cf. Demuth, 1995; Gnanadesikan, 1996; Smolensky, 1996). The claim of initial $[\mathrm{M} » \mathrm{~F}]$ ranking is not supported by Hale \& Reiss (1996) who argue that in the initial state of children's grammar the faithfulness constraints are ranked high, dominating markedness constraints $[\mathrm{F} » \mathrm{M}]$ (for discussion, see last paragraph of this section).

In OT it is assumed that children and adults share the same ranked, violable phonological constraints, but often do not share the same constraint rankings. That is, certain constraints may be more powerful in child phonology than in adult phonology. In the course of phonological development a child's system must change to approximate the target (adult) language. This entails a re- 
ranking of constraints, with demotion of the higher ranked markedness constraints below certain faithfulness constraints. With constraint demotion then, violations of lower ranked markedness constraints are no longer fatal, and the grammar of child becomes more faithful to the adult one. This view of change is different from prior derivational accounts involving phonological processes or rules that are lost, suppressed, or eliminated from the grammar over time (cf. Stampe 1973; Kiparski \& Menn 1977, among others).

The OT framework has in some important respects affinities to the framework of Natural Phonology when learning is considered, but there are also important differences. Stampe (1969:444f, 1973) assumes that the child's productions are the result of his/her applying an innate phonological system to the phonological representation. During the infancy, the innate phonological system consists of a set of universal phonological processes (e.g. deletion of unstressed syllables, simplification of clusters etc.), which simplify the phonological representation. Stampe claims that there are three ways that a child overcomes natural processes: suppression, ordering and limitation. ${ }^{6}$ Each phonetic opposition the child learns to pronounce involves some revision of the innate phonological system. The child's task in acquiring adult pronunciation is to revise all aspects of system, which separate his pronunciation from the standard. If s/he succeeds fully, the resultant system must be equivalent to that of adult speakers. One of the differences between OT and Natural Phonology is already mentioned in the previous paragraph. In OT, the activity of a markedness constraint is limited under crucial domination by a faithfulness constraint or another markedness constraint and complete inactivity cannot usually be guaranteed. In Natural Phonology complete inactivity is easily attained by suppressing a process. Among other differences, there is the markedness/ faithfulness split, which is essential to OT's explanation for homogeneity of target/heterogeneity of process, an issue that did not figure in the development of Natural Phonology ${ }^{7}$ (cf. McCarthy, 2002:51). One important issue in the phonological acquisition is the relationship between perception and production the so-called comprehension/production dilemma. This dilemma is often seen as evidence for separate comprehension and production grammars developing at different rates. The issue of perception/production contrast has been the focus of debate within the child phonology literature. It is generally accepted that a child's phonologically simplified productions are usually accompanied by relatively advanced receptive abilities. This assumption is counter to the perception hypothesis put forward in the analysis of Waterson (1971:181), that the child has incomplete perception in the initial stages of acquisition and 
'perceives only certain of the features of the adult utterance and reproduces only those that s/he is able to cope with'. Drachman (1973b) cites evidence, that there is reason to suppose that perception is not a crucial problem for the child and that his/her acoustical representation substantially matches the surface adult forms. Drachman assumes that the absence of certain forms or segments is not accidental, but it is connected with 'insecure' representation at the primary (acoustic) level. Therefore the child develops the strategy of avoidance as well as the strategy of vicarious production mechanisms. ${ }^{8}$ Traditionally are taken two approaches. One approach ascribes to the child separate lexicons for perception and production, which are governed by separate principles. ${ }^{9}$ The other approach, supported by Hale \& Reiss $(1996,1998)$, is to claim that receptive knowledge reflects a child's phonological competence, while the deviations in production are due to performance effects, including nonlinguistic, cognitive and motor processing. Hale \& Reiss (1996) claim that in the initial state of grammar, a faithful recognition of an adult word, e.g. cat [kæt] as $/ \mathrm{kæt} /$, would need high-ranked faithfulness constraints, which dominate the markedness constraints $[\mathrm{F} » \mathrm{M}]$; (a) in order to allow for the acquisition of a lexicon; (b) children have access to, and make use of, the full universal phonological feature set. Hale \& Reiss conclude that the production system must be separated from the grammar. Smolensky (1996) argues that children can hear distinctions in the speech of adults that they themselves cannot produce. The 'dilemma' for the analyst, then, is how comprehension can be so much better than production in language acquisition. Unlike Hale \& Reiss $(1996,1998)$, Smolensky argues that in the initial state of grammar markedness constraints are high-ranked, dominating faithfulness constraints $[\mathrm{M} » \mathrm{~F}]$ and that a single grammar is involved, running in both directions and can be used for production as well as for comprehension. What appears to be a difference in development is actually a result of differences in how constraint evaluation works when the grammar is used in one direction or the other. In sort, the source of the comprehension/production dilemma is a basic asymmetry in markedness constraints (they evaluate only outputs) coupled with a basic symmetry in faithfulness constraints (they evaluate input $\rightarrow$ output mappings). Throughout this study, we have been looking at productive competence: from the input Mápкос /'markos/ 'proper name, Masc.Nom', which matches the adult model, the child's grammar selects in the initial state the codaless output ['mako]. The grammar, then, is [NoCoDA » MAx]. No learning was required to come up with this grammar, since it is provided by the $[\mathrm{M} » \mathrm{~F}]$ initial state (see Section 3.3). 


\section{Overview of Greek syllable structure}

\subsection{Underlying segments in Standard Greek}

The sound system of Greek consists of the following distinctive segments:

(1) Vowels: /i, u, e, o, a/

All vowels are short, length is not distinctive in Greek. The stressed vowels are phonetically slightly longer that the unstressed vowels, but this difference is not distinctive.

(2) Consonants: /p, t, k, t $\mathrm{t}^{\mathrm{s}}, \mathrm{f}, \mathrm{v}, \theta, \partial, \mathrm{x}, \mathrm{\gamma}, \mathrm{s}, \mathrm{z}, \mathrm{m}, \mathrm{n}, \mathrm{l}, \mathrm{r} /$

The chart in (3) shows the manner and place of articulation for the consonantal phonemes. All consonants are short, length is not distinctive (long consonants occur only in some dialects, e.g. Cypriot Greek, cf. Malikouti-Drachman, 1987).

(3) Consonantal phonemes in Standard Greek

$\begin{array}{llll} & \text { Labial } & \text { Coronal } & \text { Dorsal } \\ \text { Stops } & \mathrm{p} & \mathrm{t} & \mathrm{k} \\ \text { Fricatives } & \mathrm{f}, \mathrm{v} & \theta, \mathrm{\partial} & \mathrm{x}, \mathrm{\gamma} \\ & & \mathrm{s}, \mathrm{z} & \\ \text { Affricates } & & \mathrm{t}^{\mathrm{s}} & \\ \text { Nasals } & \mathrm{m} & \mathrm{n} & \\ \text { Lateral } & & \mathrm{l} & \\ \text { Flap } & & \mathrm{r} & \end{array}$

Each of the above consonantal phonemes may correspond to more than one phonetically different variant or allophone, depending on the sounds adjacent to it, which can affect it in various ways. Below we give each phoneme with its allophones. The allophones in parentheses occur in some dialects or idiolects.

\begin{tabular}{llllll}
\hline Phoneme & Allophone(s) & Phoneme & Allophone(s) & Phoneme & Allophone(s) \\
\hline$/ \mathrm{p} /:$ & {$[\mathrm{p}],[\mathrm{b}]$} & $/ \mathrm{f} /:$ & {$[\mathrm{f}]$} & $/ \mathrm{v} /:$ & {$[\mathrm{v}]$} \\
$/ \mathrm{t} /:$ & {$[\mathrm{t}],[\mathrm{d}]$} & $/ \theta /:$ & {$[\theta]$} & $/ \mathrm{d} /:$ & {$[\mathrm{\gamma}]$} \\
& & $/ \mathrm{s} /:$ & {$[\mathrm{s}],([\mathrm{g}])$} & $/ \mathrm{z} /:$ & {$[\mathrm{z}]([\mathrm{g}])$} \\
$/ \mathrm{k} /:$ & {$[\mathrm{k}],[\mathrm{g}]$} & $/ \mathrm{x} /:$ & {$[\mathrm{x}],[\mathrm{c}]$} & $/ \mathrm{\gamma} /:$ & {$[\mathrm{\gamma}],[\mathrm{j}]$} \\
& {$[\mathrm{c}],[\mathrm{i}]$} & & & & \\
$/ \mathrm{t}^{\mathrm{s}} /:$ & {$\left[\mathrm{t}^{\mathrm{s}}\right],\left[\mathrm{d}^{\mathrm{z}}\right]$} & & & & \\
$/ \mathrm{m} /:$ & {$[\mathrm{m}],([\mathrm{m}])$} & $/ \mathrm{l} /:$ & {$[\mathrm{l}],([\mathrm{K}],[\mathrm{t}])$} & & \\
$/ \mathrm{n} /:$ & {$[\mathrm{n}],[\mathrm{n}],[\mathrm{p}]$} & $/ \mathrm{r} /:$ & {$[\mathrm{r}]$} & & \\
\hline
\end{tabular}


The voiceless plosives /p, $\mathrm{t}, \mathrm{k} /$ occur in all environments except after a nasal. After a nasal they are realized either as simple voiced plosives $[\mathrm{b}, \mathrm{d}, \mathrm{g}]^{10}$ or as prenasalized plosives [ ${ }^{\mathrm{m}} \mathrm{b},{ }^{\mathrm{m}} \mathrm{d}, \mathrm{m}_{\mathrm{g}}$ ], e.g. the phonological representation $/ \mathrm{kaN}$ pana/ 'bell' may be phonetically realized as $[$ ka'bana $] \sim[$ kam'bana $] \sim\left[\mathrm{ka}^{\mathrm{am}}-\right.$ bana]. In word initial position the voiced plosives are mostly realized without the nasal, e.g. the phonological representation /Npora/ is realized as ['bora] (the prenasalized phonetic realization ['mbora] is also attested, cf. Kappa, 1995). The presence or absence of nasal before the voiced plosives and the degree of nasality is optional and vary in accordance with sociolinguistic factors such as the speaker's origin or age, the formality of the context etc. In cases of loan words which have not been assimilated completely to the Greek phonological system, the sequences of / Nasal + voiceless Plosive/ do not give rise to the realization of voiced plosives, e.g. [sam'panja] 'champaign', [kom'pjuter] 'computer'.

The palatalized allophones $[c, y]$ of the phoneme $/ \mathrm{k} /$ are realized before the front vowels /i, e/, e.g. the phonological representation /'kipos/ 'garden' is realized as ['cipos].

The segment $/ \mathrm{t}^{\mathrm{s}} /$ may be analysed as a single phoneme, i.e. a voiceless dental affricate or as forming a cluster consisting of $[\mathrm{t}+\mathrm{s}]$. The voiced allophone $\left[\mathrm{d}^{\mathrm{z}}\right]$ is marginal. It can also be analyzed either as the phonetic variant of the single segment $/ \mathrm{t}^{\mathrm{s}} /$ after a nasal or as a cluster consisting of $[\mathrm{d}+\mathrm{z}]$. In the present study we are not going into the investigation of mono- or bisegmental status of the segment $\left[\mathrm{t}^{\mathrm{s}}\right]^{11}$ (on affricates in child language, cf. Kappa 1998a).

The palatalized allophones $[c ̧]$ and $[\mathrm{j}]^{12}$ of the fricative phonemes $/ \mathrm{x} /$ and $/ \gamma /$ occur before the front vowels /i, e/, e.g. /'xeri/ 'hand' is realized as ['çeri].

In some dialects or idiolects, in the environment of front vowels, the dental strident consonants /s/ and /z/ may be phonetically realized as the palatalized allophones [S] and [3] respectively, e.g /kra'si/ 'wine' may be realized as [kra'fi].

The lateral consonant /l/ may be realized as its palatalized variant $[\Lambda]$, e.g. /'likos/ 'wolf' becomes ['Kikos], as well as a velarized variant [ 1 ] before the nonfront vowels /a, o, u/, e.g. /'ela/ is realized as ['eła] (in some north dialects or idiolects).

The bilabial nasal phoneme $/ \mathrm{m} /$ may also have a labiodental variant [m], if it occurs before a labiodental fricative, e.g. /'simfono/ 'consonant' may be realized as ['simfono] (cf. Holton et al. 1997).

The dental nasal phoneme $/ \mathrm{n} /$ may have a palatalized variant, if it occurs before the high front vowel/i/, e.g. the form /'nikos/ 'Nick' is realized as ['nikos] in some dialects or idiolects, but without palatalization as ['nikos] in Standard 
Greek. The allophone [n] is also a result of combination, viz. $/ \mathrm{n}+\mathrm{i}+$ vowel/, when /i/ is unstressed, e.g. the word viáta 'youth' consists of the phonemes /ni'ata/, but it is phonetically realized as ['nata].

The phoneme /n/ may also have a velar variant [n], which occurs before

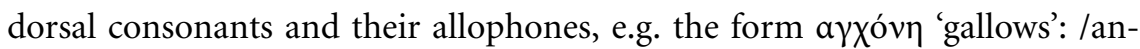
'xoni/ is realized as [an'xoni].

\subsection{Surface onsets}

In this section we will present briefly the possible onset types and the coda condition of Standard Greek. ${ }^{13}$

(5) Single Onsets

Any consonant may occur word- or syllable-initially as a single onset.

(6) 2-member Onsets

The tautosyllabic onsets ${ }^{14}$ consisting of [OBstruent + Sonorant] may be realized in word- or syllable-initial position, obeying a minimal sonority distance $\geq 4$ (cf. Malikouti-Drachman, 1984). Homorganic sequences do not surface, e.g. ${ }^{\star}[\mathrm{pm}],{ }^{\star}[\mathrm{tl}, \mathrm{tn}],{ }^{\star}[\mathrm{sl}, \mathrm{sn}, \mathrm{zn}, \mathrm{zl}, \mathrm{zr}]$ due to $\mathrm{OCP}_{\mathrm{PLACE}}{ }^{15}$ [STOP + Sonorant]: [pn, kn, pl, bl, pr, br, tr, dr, kl, kr, gl, gr], e.g. ['pleno] 'I wash', ['krio] 'cold'

[Fricative + Sonorant]: [fl, fr, vl, vr, $\theta \mathrm{n}, \theta \mathrm{l}, \theta \mathrm{r}, \partial \mathrm{r}, \mathrm{xn}, \mathrm{xl}, \mathrm{xr}, \mathrm{\gamma n}, \mathrm{\gamma l}$, yr], e.g. ['floya] 'flame', ['ynomi] 'opinion', [ðromos] 'street' etc.

In Greek [Овstruent+ Oвstruent] clusters also surface whose members agree in voicing and violate the minimal sonority distance of $\geq 4$, therefore they are also referred as 'antisonority' clusters.

[STOP + STOP]: [pt, kt]. These clusters are borrowings from katharevousa, (formal use of language) restricted only to a specific discourse (formal, scientific, etc). ${ }^{16}$

[pte'ro] 'wing', [kti'po] 'I hit'

[Stop + Fricative]: [ps, ks], e.g. ['ksenos] 'foreigner', [psi'çi] 'soul'

[Fricative + Stop]: [sp, st, sk, ft, xt], e.g. ['spiti] 'house', [sta'fili] 'grape', [ski'ni] 'rope' etc.

[Fricative + Fricative]: [sf, s $\theta, \mathrm{sx}, \mathrm{x} \theta, \mathrm{f} \theta]^{17}$ and [zv, zy, vð, vy, $ð$ ð], e.g.

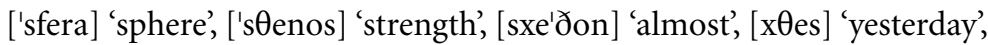
[fӨi'no] 'cheap', ['zverkos] 'neck', [zyu'ros] 'curly', ['vðela] 'leech' etc. 
(7) 3-member Onsets:

Clusters consisting of [Овstruent + OBStruent + Sonorant] surface in onset position too. The first and the second member of these clusters violate the minimal sonority distance of $\geq 4$ ('antisonority' clusters). Among them are clusters consisting of:

[Fricative + Stop + Sonorant], e.g. [skn, spl, spr, str, skl, skr ${ }^{18}$ occur in word- or syllable-initial position and the clusters [ftr, xtr], which occur only in word-medial position.

Word-initial

Word-medially [stra'tos] 'army' ['astro] 'star' ['sproxno] 'I push' ['aspro] 'white' etc.

['raftra] 'dressmaker'

[sfiri'xtra] 'whistle'

[Fricative + Fricative + Sonorant] clusters, eg. [sfr, sxr, sxn, s $\theta \mathrm{m}$, $\mathrm{x} \theta \mathrm{r}$ ] occur only in word-medial position, with exception of cluster [sfr] which may also occur word-initially.

Word-initial Word-medially [sfra'yiða] 'stamp' [a'sfrayistos] 'unstamped'

[i'sxnos] 'lean'

['as $\theta \mathrm{ma}]$ 'asthma'

[e'x $\theta$ ros] 'enemy'

$[$ STOP + STOP + SONORANT $]$, e.g. $[\mathrm{ptr}, \mathrm{ktr}, \mathrm{kpl}]$ occur only in wordmedial position.

$\begin{array}{ll}\text { Word-medially } \\ \text { [i'ktros] } & \text { 'miserable' } \\ \text { ['katoptro] } & \text { 'mirror' } \\ \text { ['ekpliksi] } & \text { 'surprise' }\end{array}$

(8) 4-member Onsets:

Clusters with four members are rare. They consist of [FrIC/STOP + FrICATIVE + Stop + Sonorant], i.e. [fspl, fstr, kstr]. They are usually created through prefixation, as in (b) and occur only in word-medial position.

Word-medially

a. [a'fstria] 'Austria'

b. [efspla'xnia] 'compassion', [ekstra'tia] 'campaign' 


\subsection{Codas}

In the native vocabulary of (spoken) Standard Greek may surface phonetically as coda word-final the coronal segments [s, n], e.g. [stra'tos] 'army', ['pezun] '(they) play'. The segment $[\mathrm{n}]$ is often accompanied by an epenthetic vowel creating an open syllable, e.g. ['pezun] ['pezune]. Besides the native segments $[\mathrm{s}, \mathrm{n}]$ are also attested other segments as coda final, as in onomatopoetic items like bum-bum or due to borrowings of foreign origin (9c), e.g the segments [r], $[1],[\mathrm{m}],[\mathrm{p}],[\mathrm{t}],[\mathrm{k}]$, etc. Besides the single segments occur final codas with clusters of two or (rarely) three members, e.g. [-lf]: 'golf', [-lt]: 'volt', [-kt]: 'tact', [-st]: 'test', [-nks]: 'tanks', etc. We assume that these borrowings are

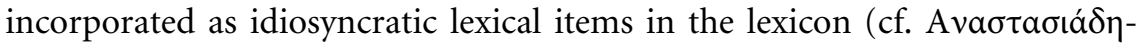
$\Sigma v \mu \varepsilon \omega v i \delta \eta, 1994)$. Greek language may also create new forms in accordance with the coda pattern of the loan words, e.g. the abbreviated [pro'kat] 'preconstructed' (from the full form [prokataskeva'zmeno]) or acronyms, e.g. П.А.Г.O.К. [pa'sok], Н.А.П.А.П [il'pap] etc. The (Greek) forms indicate that, under specific conditions (e.g. specific discourse, non-linguistic factors etc), Greek language has a tendency to relax the constraint on coda-final segments. The segments [ $\mathrm{s}, \mathrm{n}, \mathrm{r}]$ occur as coda-final in words belonging to the vocabulary of katharevousa, as well as, two-member final clusters, e.g. [-fs], [-ps], [-ks] in words like $\alpha \dot{\alpha} \theta \rho \alpha \xi$ ['an $\theta$ raks] 'coal' etc. Words with such clusters are used rarely, only in a specific discource.

Word-internally codas are permitted (10), provided that they are weaker than the following onsets (cf. Drachman \& Malikouti-Drachman, 1997; Malikouti-Drachman, 2001).

(9) Coda word final

a. Demotic (spoken) Greek [stra'tos] 'army' [ka'Oikon] 'duty'

c. Borrowings

[r]: 'computer'

[1]: 'festival'

[m]: 'forum'

[p]: 'check-up'

[t]: 'watt'

[k]: 'rock' b. Katharevousa

['iðor] 'water'

['anӨraks] 'coal'

['miops] 'shortsighted'

[vasi'lefs] 'king' 


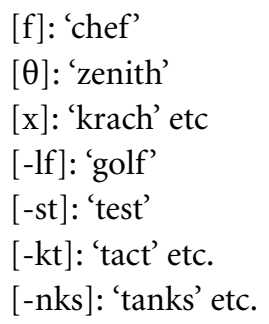

(10) Coda word internally

[ksan.'Өos] 'blond'

['al.ma] 'jump'

['ðer.ma] 'skin

['ef.kolo] 'easy'

The canonical (native) syllable types may be given in the schema: CCCVC. ${ }^{19}$ The maximal initial sequence is exemplified by the word stra'tos 'army'.

\section{On the acquisition of syllable structure}

3.1 The realization of (target) single onsets

At the early word-stage Sofia realizes only CV (core) syllables, with initial stops, nasals and laterals (11). The input fricatives are realized as stops, i.e. the child's phonology shows no contrast for the feature [continuant] and the child realizes only the unmarked [-cont] feature (cf. 11 b-f).

$\begin{array}{lllll} & \text { Target word } & \text { Child's output } & \text { Gloss } & \text { Age } \\ \text { a. } & \text { ku'ti } & \text { ku'ti } & \text { 'box' } & 2 ; 2 \\ \text { b. } & \text { pe'ði } & \text { pe'di } & \text { 'child' } & 2 ; 0 \\ \text { c. } & \text { 'feta } & \text { 'peta } & \text { 'slice' } & 2 ; 2 \\ \text { d. } & \text { 'vazo } & \text { 'bado } & \text { 'vase' } & 2 ; 3,21 \\ \text { e. 'Өelo } & \text { 'telo } & \text { '(I) want' } & 2 ; 4,18 \\ \text { f. } & \text { 'zoni } & \text { 'doni } & \text { 'belt' } & 2 ; 5,9\end{array}$

The observation that children start with plosives in onset position was made by Jakobson (1968) and is also widely reported in the bibliography. The first contrast to appear is that between a vowel and a consonant, a plosive being the most prototypical consonant. The contrast is maximal: a complete closure (preferably a labial) followed by a wide opening for the vowel. There is also a maximum rise in sonority slope toward the vowel (cf. Clements, 1990). A 
plosive is an optimal syllable margin possessing the features [-sonorant, +consonantal, -continuant]. Drachman (1978:125) assumes that the stoppreference derives from a context-free process (Fricative $\rightarrow$ STOP) due to the special tract-control conditions for the child. The child has not mastered yet his vocal tract and when s/he has to produce a target obstruent segment, s/he "employs" a ballistic rather than a continuous-control mechanism in order to produce what is easiest. Therefore the child produces a stop rather than the intended fricative preserving the place features of the target segment. ${ }^{20}$ We assume, in terms of OT, that the general markedness constraint ${ }^{*}$ [cont], which prohibits the fricatives to surface, is active in child's phonology. The onsetless target words are 'repaired' either by reduction of the onsetless syllable (12a,c) or by copying in order to fill in the empty onset position (12b). Otherwise the child avoids onsetless target words.

$\begin{array}{lllll} & \text { Target word } & \text { Child's output } & \text { Gloss } & \text { Age } \\ \text { a. e'ðo } & \text { do } & \text { 'here' } & 1 ; 10 / 1 ; 10,7 \\ \text { b. e'ðo } & \text { de'do } & \text { 'here' } & 1 ; 10,7 \\ \text { c. } & \text { e'ci } & \text { ci } & \text { 'there' } & 1 ; 10,7\end{array}$

The basic constraints which operate on output structure and are relevant for the above data in (11) and (12) are listed in (13a,b).

(13) Basic constraints

a. Markedness constraints

ONSET Syllables must have onsets (Prince \& Smolensky, 1993)

* [cont] No continuant obstruents.

b. Faithfulness constraints (cf. McCarthy \& Prince, 1995).

$\operatorname{MAx}(\mathrm{I}-\mathrm{O})$ Every segment in the input has a correspondent in the output. No deletion.

DeP(I-O) Every segment in the output has a correspondent in the input. No epenthesis. ${ }^{21}$

IDENT[cont] If an input segment has the feature value [ $\alpha$ Continuant], then its output correspondent has to be [ $\alpha$ Continuant]

For each of the target forms, in (11) and (12), the above constraints ranked in a particular order, as in (14), must evaluate different output candidates to determine which one is the most optimal. Any change in the constraint ranking in (14) can be considered as another development stage.

(14) Constraint ranking

OnSET ${ }^{*}$ cont $»\{\operatorname{Max}(\mathrm{I}-\mathrm{O}), \operatorname{Dep}(\mathrm{I}-\mathrm{O})\} » \operatorname{Ident}[$ cont $]$ 
We assume that at this stage ONSET is obligatory, thus undominated. The ${ }^{\star}$ [cont] markedness constraint must also be highly ranked, because no continuants surface. Violation of ONSET and ${ }^{*}$ [cont $]$ is more serious than a violation of the equally ranked lower constraints $\operatorname{Max}(\mathrm{I}-\mathrm{O})$ and $\operatorname{Dep}(\mathrm{I}-\mathrm{O})$. The IDENT [cont] constraint is the lowest in the ranking because it is always violated at this stage. The ranking given in (14) can account for the variability that is exhibited in this child's productions for target word-initial onesetless syllables, by allowing for either deletion or epenthesis to created well-formed unmarked CV-syllables (cf. examples in $12 \mathrm{a}, \mathrm{b})$. MAx(I-O) and $\operatorname{DeP}(\mathrm{I}-\mathrm{O})$ are not hierarchically ranked with respect to one another, but both constraints occur as a part of the same stratified domination hierarchy (cf. Tesar \& Smolensky, 1998, 2000) or partial constraint ranking, $\{\operatorname{MAx}(\mathrm{I}-\mathrm{O}), \operatorname{DEP}(\mathrm{I}-\mathrm{O})\}$, that allows for multiple candidates to be optimal (cf. Demuth, 1995, 1997). The multiple outputs are allowed only if constraints violated within a given strata are not evaluated gradiently. The following example in tableau (15) matches the case of multiple outputs.

Adult form: [e'ðo] $\rightarrow$ [de'do] [do] 'here', 1;10 /1;10,7

\begin{tabular}{|c|c|c|c|c|c|}
\hline$e^{\prime} ð o$ & ONSET & ${ }^{*}$ cont & $\{\operatorname{Max}(\mathrm{I}-\mathrm{O})$, & $\operatorname{Dep}(\mathrm{I}-\mathrm{O})\}$ & IDENT[cont] \\
\hline a. $\quad$ e $\left.e^{\prime} \partial o\right]$ & * & * & $\checkmark$ & $\checkmark$ & $\checkmark$ \\
\hline b. [e'do] & * & $\checkmark$ & $\checkmark$ & $\checkmark$ & * \\
\hline c. $\circledast[\mathrm{de}$ 'do] & $\checkmark$ & $\checkmark$ & $\checkmark$ & * & * \\
\hline d. $[\mathrm{do}]$ & $\checkmark$ & $\checkmark$ & * & $\checkmark$ & * \\
\hline
\end{tabular}

In the above tableau (15), both candidates $(15 \mathrm{a}, \mathrm{b})$ violate the undominated constraint OnSET, therefore both are not selected as optimal outputs. An epenthesized or a deleted segment would result in a more harmonic output form, as the candidates (15c) and (15d) respectively, than a form without onset (15a or $15 b)$ and/or violation of the high ranked ${ }^{*}$ [cont] constraint (15a). We expect than one of the candidates $(15 \mathrm{c})$ or $(15 \mathrm{~d})$ will be chosen as the optimal output. The candidate $(15 \mathrm{c})$ violates the $\operatorname{DEP}(\mathrm{I}-\mathrm{O})$ due to the epenthesis of $[\mathrm{d}]$ in onset position, while the candidate (15d) violates the $\operatorname{Max}(\mathrm{I}-\mathrm{O})$ constraint due to the deletion of initial vowel [e]. In spite of these different violations, both candidates are equally valued by the grammar and both are selected as optimal outputs due to the fact, that the constraints MAX and DeP are not hirarchically ranked with respect to one another. Both of the selected candidates (15c,d) violate the constraints MAX and DeP, but they do so equally, i.e. these two outputs do no compete with each other. Therefore, there is not only one 
optimal (surface) output, but there are multiple outputs (variation) for the given input form. The demoted IDENT[cont] constraint plays no role in the selection of the optimal output, because it is always violated at this stage.

In the case of output candidates, as in tableau (16), the violation of the highly ranked ${ }^{*}$ [cont] eliminates the output candidate (16a). The output candidate (16b) satisfies the highly ranked ${ }^{*}$ [cont] constraint, and it is chosen as optimal, although it violates the faithfulness constraint IDENT[cont]. The constraints MAX and DEP are irrelevant for the selection of the optimal output.

(16) Adult form: [pe'ði] $\rightarrow$ [pe'di] 'child', 2;0

\begin{tabular}{|c|c|c|c|c|c|}
\hline pe'ði & ONSET & ${ }^{*}$ cont & $\{\operatorname{Max}(\mathrm{I}-\mathrm{O})$ & $\operatorname{Dep}(\mathrm{I}-\mathrm{O})\}$ & IDENT [cont] \\
\hline $\begin{array}{l}\text { a. } \quad\left[\mathrm{pe}^{\prime} \partial \mathrm{i}\right] \\
\text { b. }\left[\mathrm{pe} \mathrm{e}^{\prime} \mathrm{di}\right]\end{array}$ & $\checkmark$ & *! & & & $\begin{array}{l}\checkmark \\
*\end{array}$ \\
\hline
\end{tabular}

In the course of phonological development the child selects for production a few target words beginning with a stressed vowel and realizes them almost faithfully, without using anymore the repair strategies of deletion or epenthesis (17).

$\begin{array}{lllll} & \text { Target word } & \text { Child's output } & \text { Gloss } & \text { Age } \\ \text { a. } & \text { e'ðo } & \text { e'do } & \text { 'here' } & 2 ; 0 \\ \text { b. 'oçi } & \text { 'oci } & \text { 'no' } & 2 ; 0-2 ; 5 \\ \text { c. 'ena } & \text { 'ena } & \text { 'one' } & 2 ; 0\end{array}$

The transition to more faithful outputs is signaled with a reranking of the constraints given in (14). The faithfulness constraints $\operatorname{MAx}(\mathrm{I}-\mathrm{O})$ and $\mathrm{DEP}(\mathrm{I}-\mathrm{O})$ are promoted and obscure the markedness constraints ONSET and * [cont] (ranking in 18), but the ${ }^{\star}$ [cont] constraint is always active and prevents the faithful realization of fricatives in forms as the above outputs $(17 \mathrm{a}, \mathrm{b})$.

(14) Onset $»{ }^{*}$ cont $»\{\operatorname{Max}(\mathrm{I}-\mathrm{O}), \operatorname{Dep}(\mathrm{I}-\mathrm{O})\} » \operatorname{Ident}[$ cont $]$ (CV-structures)

(18) $\operatorname{Max}(\mathrm{I}-\mathrm{O}), \operatorname{Dep}(\mathrm{I}-\mathrm{O}) » \operatorname{OnSET} »{ }^{*}$ cont $» \operatorname{Ident}[$ cont] (V-Structures)

In the following tableau (19) the reranking of constraints in (18) results in another output form compatible with the developmental stage. The promoted faithfulness constraints MAX and DEP force more marked structures due to their high ranking and rule out the candidate (19b) due to segment epenthesis and the candidate (19c) to due to segment deletion. Both candidates (19a, 19d) satisfy the highly ranked faithfulness constraints MAX and DEP and violate the markedness constraint ONSET, due to the onsetless word-initial syllable The decision for the optimal output is made by the satisfaction of markedness constraint ${ }^{\star}$ [cont], 
that forbids fricatives. The candidate (19a), surfacing a fricative, is ruled out due to fatal violation of the constraint ${ }^{*}$ [cont], while the candidate (19d), realizing a plosive, satisfies the constraint and it is selected as optimal.

(19) Adult form: [e'ðo] $\rightarrow$ [e'do] 'here', 2;0

\begin{tabular}{|c|c|c|c|c|c|}
\hline$e^{\prime \prime \partial o}$ & $\operatorname{Max}(\mathrm{I}-\mathrm{O})$ & Dep $(\mathrm{I}-\mathrm{O})$ & ONSET & ${ }^{*}[$ cont $]$ & IDENT [cont] \\
\hline a. $\quad$ [e'ðo] & $\checkmark$ & $\checkmark$ & * & *! & $\checkmark$ \\
\hline b. [de'do] & $\checkmark$ & * & $\checkmark$ & $\checkmark$ & * \\
\hline c. [do] & * & $\checkmark$ & $\checkmark$ & $\checkmark$ & * \\
\hline d. $\because\left[e^{\prime} d o\right]$ & $\checkmark$ & $\checkmark$ & * & $\checkmark$ & * \\
\hline
\end{tabular}

More data of target fricatives that surface as stops follow in (20). We assume that the child's outputs in (20) are the result of the domination of the highly ranked general markedness constraint ${ }^{*}$ [cont] over the faithfulness constraint IDENT[cont]. This corresponds to the developmental STAGE I in the acquisition of fricatives (cf. Kappa, 2000).

\begin{tabular}{|c|c|c|c|}
\hline Target word & Child's output & Gloss & Age \\
\hline$e^{\prime \gamma o}$ & e'do & 'here' & $2 ; 0$ \\
\hline$\rightarrow$ fos & po & 'light' & $2 ; 0$ \\
\hline$\rightarrow$ 'volta & 'bota & 'walk' & $2 ; 2 / 2 ; 4,11 / 2 ; 6,21$ \\
\hline$\rightarrow$ bu'fan & bo'pa & 'anorak' & $2 ; 2$ \\
\hline 'oçi & 'oci & 'no' & $2 ; 0-2 ; 5$ \\
\hline flo'yera & 'gela & 'flute' & $2 ; 2 ; 20$ \\
\hline$\rightarrow$ 'olya & 'oga & 'proper name' & $2 ; 3,18$ \\
\hline so'fia & pi'pia & 'proper name' & $2 ; 3,18$ \\
\hline 'vazo & 'bado & 'vase' & $2 ; 3,21$ \\
\hline 'Өelo & 'telo & '(I) want' & $2 ; 4,18$ \\
\hline 'zoni & 'doni & 'belt' & $2 ; 5,9$ \\
\hline$\rightarrow$ ðеs & des & 'see', 2.IMP & $2 ; 5,23$ \\
\hline
\end{tabular}

The faithful realization of fricatives is relatively late. Our data provide evidence that only the fricative /s/ surfaces earlier in coda word final, about the age of 2;2 (see Section 3.3) and this corresponds to the developmental stage II in the acquisition of fricatives. The fricatives are realized later in onset position (about the age of 2;6, developmental sTAGE III/IV), signaling the introduction of a manner contrast. This contrast is attributed to the promotion of the faithfulness constraint IDENT [cont] that obscures the activation of the general markedness 
* [cont] constraint, viz. IDENT [cont $]{ }^{*}[$ cont $]$. Our data provide evidence that the changes in the realization of target fricatives will be carried out gradually. The data in (21) show, that although the word medial (target) fricatives are realized faithfully, the word initial (target) fricatives are still realized as stops. We assume that this is a TRANSITION STAGE III in the realization of fricatives, where plosives are still favoured as optimal segments in word-initial position.

$\begin{array}{lllll} & \text { Target word } & \text { Child's output } & \text { Gloss } & \text { Age } \\ \text { a. 'vixa } & \text { 'bixa } & \text { 'cough', ACC.sG } & 2 ; 5,23 \\ \text { b. 'çipi } & \text { 'piçi } & \text { 'hippy', ACC.sG } & 2 ; 5,23 \\ \text { c. } & \text { çi'paci } & \text { pi'xaci } & \text { 'hippy', DIM } & 2 ; 6,13\end{array}$

This stop-preference indicates that the general markedness constraint * [cont], although demoted, has left its 'traces'. In order to capture such cases as in (21) we assume that the context-sensitive markedness constraint word ${ }^{\star}$ [cont] is active, militating against the feature value [+cont] in the specific (word-initial) position and prevents a word from beginning with a fricative. ${ }^{22}$ Therefore the constraint ${ }_{\text {word }}{ }^{\star}$ [cont] must be ranked above the IDENT[cont] in the constraint ranking in (22), but the general markedness constraint ${ }^{\star}$ [cont] must be lower ranked, dominated by the IDENT[cont], so that medial input fricatives may surface faithfully.

$$
\text { word }^{\star}[\text { cont }] » \operatorname{IDENT}[\text { cont }] \text { » }{ }^{\star}[\text { cont }]
$$

In the following tableau (23) the output candidate (23a) violates the dominated word $^{*}[$ cont $]$ and is ruled out. Both candidates $(23 \mathrm{~b}, \mathrm{c})$ satisfy the highly ranked constraint ${ }_{\text {word }}{ }^{\star}$ [cont], because both start with a non-fricative. The decision for the optimal output is made by the constraint IDENT [cont]. The candidate (23b) violates the high-ranked faithfulness constraint IDENT[cont] twice, while the candidate $(23 \mathrm{c})$ only once, i.e. it incurs a minimal violation, ${ }^{23}$ therefore the form $(23 \mathrm{c})$ is selected as the optimal output. The violation of the demoted general markedness constraint ${ }^{*}$ [cont] play no role in the selection of optimal output. (A constraint IDENT[voice], demanding faithfulness for the feature [ $\alpha$ Voice] between input and output segment, is also involved, but plays no role in the selection of optimal candidate. Therefore we do not mention it). 
(23) Adult form: ['vixa] $\rightarrow$ ['bixa] 'cough', ACc.sG, 2;5,23

\begin{tabular}{|c|c|c|c|}
\hline 'vixa & $\operatorname{word}^{*}[$ cont $]$ & IDENT [cont] & ${ }^{*}$ cont \\
\hline a. ['vixa] & * & $\checkmark$ & ** \\
\hline b. ['bika] & $\checkmark$ & $* *$ ! & $\checkmark$ \\
\hline c. $[$ 'bixa] & $\checkmark$ & * & * \\
\hline
\end{tabular}

The data, in $(21 b, c)$ repeated in $(24 a, b)$, show that at this developmental stage the child confronts his 'desire' for plosives in word-initial position, using also the strategy of metathesis. Consonants are moved, not deleted and features are generally preserved, i.e. the children avoid violations of $\operatorname{Max}(\mathrm{I}-\mathrm{O})$ and IDENT[cont]/IDENT[Place], respectively. Besides, if the child has to produce a word, which has obstruents with more than one place of articulation, she 'favours' to produce the obstruents in a front to back order (labials wordinitially). Therefore she uses metathesis in order to confront words starting with a place of articulation other than labial (cf. Kappa, 1999, 2001). The restriction is not strictly on particular features appearing in particular positions, but on the order of the place features when more than one is present, ${ }^{24,25}$ therefore it seems that the child uses metathesis in a systematic fashion. More data in $(24 \mathrm{c}, \mathrm{d}, \mathrm{e})$ support this assumption (cf. also, Section 3.2.2, cases in (39c, 42b/44, 45d/49)).

$\begin{array}{lllll} & \text { Target word } & \text { Child's output } & \text { Gloss } & \text { Age } \\ \text { a. } & \text { 'çipi } & \text { 'piçi } & \text { 'hippy', ACc.sG } & 2 ; 5,23 \\ \text { b. çi'paci } & \text { pi'xaci } & \text { 'hippy', DIM } & 2 ; 6,13 \\ \text { c. 'tubes } & \text { 'pudes } & \text { 'somervaults' } & 2 ; 3,18 / 2 ; 4,11 \\ \text { d. 'kupa } & \text { 'puka } & \text { 'cup' } & 2 ; 4,4 / 2 ; 9 \\ \text { e. } & \text { 'kapa } & \text { 'paka } & \text { (child's last name) } & 2 ; 9,15\end{array}$

The use of metathesis provides a means of pronouncing an adult word without violating a preferred syllable-structure or feature order pattern where the labial consonant is preferred to dorsal/coronal ones as onset in word initial position. Metathesis, like the word selectivity, which typically precedes it, calls our attention to the child's desire to respect specific phonological output constraints. Metathesis is one of many patterns, which illustrate children's willingness to violate faithfulness constraints (i.e. misproduce a target word) in order to maintain forms, which are unmarked within their individual phonological systems (Velleman, 1996). Metathesis violates the LinEARITy constraint, which says that the input and the corresponding output segments must have the same linear order (McCarthy \& Prince, 1995). The LinEarity constraint must be ranked very low, but allows the child to avoid violations of MAx and 
IDEnT[cont]. The highly-ranked Align(LABial-left) specifies that the labial feature will appear as close to the left edge (onset) as possible. In (25) we reformulate the constraint ranking established in (22).

$$
\operatorname{Align}(\text { labial-left }) »{ }_{\text {word }}{ }^{*}[\text { cont }] » \operatorname{Ident}[\text { cont }] »{ }^{*}[\text { cont }] » \operatorname{Linearity}
$$

The constraint interaction of ALIGN(LABIAL-left) and word $^{*}$ [cont] in (25) yields the optimal output in such cases as the examples $(24 a, b)$, where metathesis phenomena occur (see tableau 26).

(26) Adult form: ['çipi] $\rightarrow$ ['piçi] 'hippy', ACc.sg 2;5,23

\begin{tabular}{|c|c|c|c|c|c|}
\hline çipi' & $\begin{array}{c}\text { Align } \\
\text { (LAB-left) }\end{array}$ & $\mathrm{wd}^{\star}[$ cont $]$ & $\begin{array}{l}\text { IDENT } \\
\text { [cont] }\end{array}$ & ${ }^{\star}$ cont & LINEARITY \\
\hline a. ['çipi] & * & * & $\checkmark$ & * & $\checkmark$ \\
\hline b. ['cipi] & * & $\checkmark$ & * & $\checkmark$ & $\checkmark$ \\
\hline $\begin{array}{ll}\text { c. } & \text { ['fici] }\end{array}$ & $\checkmark$ & $* !$ & $\checkmark$ & * & * \\
\hline d. ['piçi] & $\checkmark$ & $\checkmark$ & $\checkmark$ & * & * \\
\hline
\end{tabular}

The candidates $(26 \mathrm{a}, \mathrm{b})$ are excluded as optimal outputs, because both have a dorsal segment word-initially, therefore both violate ALIGN (LABIAL-left). The candidates (26c) and (26d) compete with one another, because, due to metathesis, both satisfy the highly ranked ALIGN(LABIAL-left). The decision for optimal output is made by the satisfaction of constraint ${ }_{\text {word }}{ }^{*}$ [cont], that forbids fricatives at the beginning of the word. The candidate $(26 \mathrm{c})$ is ruled out, because it starts with a fricative and violates ${ }_{\text {word }}{ }^{*}$ [cont] constraint, while the candidate starts with the (metathesized) plosive, satisfies the constraint and is selected as an optimal output. In the course of phonological development the constraint ALIGN (LABIAL-left) remains active and highly ranked for a long time, as shown in the example in (24e), (see also Section 3.2.2, cases). Only the constraint $_{\text {word }}{ }^{\star}$ [cont] is demoted due to the promotion of faithfulness IDENT [cont] and this signals the faithful realization of input fricatives (STAGE IV), cf. the data in (27).

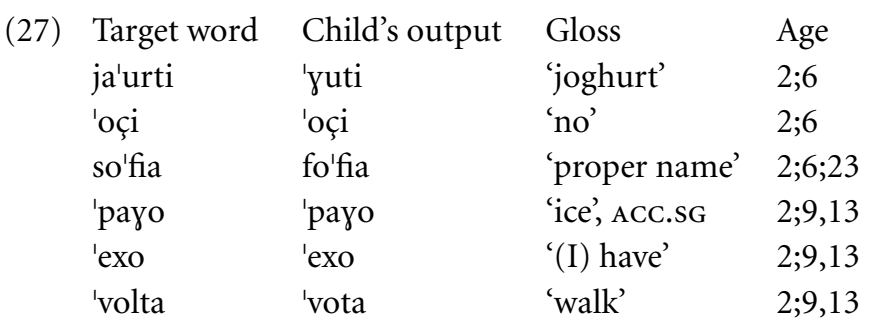




$\begin{array}{llll}\text { fos } & \text { fos } & \text { 'light' } & 2 ; 9,13 \\ \text { vi'vlio } & \text { vi'lio } & \text { 'book' } & 2 ; 9,13 \\ \text { 'toso } & \text { 'toso } & \text { 'so much' } & 2 ; 9,13 \\ \text { xri'sula } & \text { 'sula } & \text { 'proper name' } & 2 ; 9,15 \\ \text { 'olya } & \text { 'oya } & \text { 'proper name' } & 2 ; 9,13\end{array}$

The faithful realization of target fricatives in (27) is attributed to the promotion of the faithfulness constraint IDENT[cont] that obscures the activation of the contextual and general markedness ${ }^{*}$ [cont] constraints. This is one more piece of evidence for the description of phonological stages as a constraint reranking. In (28) we establish the reranking of constraints due to the promotion of Ident[cont]. The constraint Align(Labial-left) is activated if there are obstruents with two different places of articulation within the same word.

$$
(\operatorname{Align}(\text { Lab-left })) » \operatorname{Ident}[\text { cont }] » \text { word }^{*}[\text { cont }] »{ }^{*}[\text { cont }] » \operatorname{LinEarity}
$$

In the tableau (29) the output candidate (29a) violates the highly ranked IDENT [cont] constraint, because the input fricative $[\gamma]$ is not realized faithfully, but as the plosive $[\mathrm{g}]$. The candidate (29b) satisfies IDENT [cont] and it is chosen as optimal output. (For the sake of simplification we illustrate only the relevant constraints for the selection of the optimal output).

(29) Adult form: ['payo] $\rightarrow$ ['payo] 'ice', Acc.sg 2;9,13

\begin{tabular}{|c||c|c|}
\hline 'payo & IDENT[cont] & ${ }^{*}$ cont \\
\hline \hline a. $\quad[$ 'pago] & $* !$ & $\checkmark$ \\
b. $\leftrightarrow[$ 'payo] & $\checkmark$ & $*$ \\
\hline
\end{tabular}

\subsection{The realization of (target) complex onsets}

A typical problem in phonological acquisition is the development of consonant clusters. It has been reported in the literature that children always pass through a stage in which consonant clusters are produced 'incorrectly'. The incorrect cluster productions may vary across children and across cluster types, but all these productions tend to be unmarked in structure (cf. among others, Barlow \& Dinnsen 1998; Chin \& Dinnsen, 1992; Fikkert, 1994, Gnanadesikan, 1996). Greenlee (1974) proposed that cluster development may be characterized through the following four stages. ${ }^{26}$

Stage I: Deletion of the entire cluster.

Stage II: Reduction of the cluster to a single consonant. 
Stage III: Realization of the cluster with substitution of one segment. Stage IV: Correct production of the cluster.

Stage II seems to be the most common type, i.e. reduction of the cluster to a single consonant, in order that unmarked or less marked syllable shapes surface. If the target cluster consists of [Овstruent+Sonorant] segments, then it is reduced to the less sonorous (or to the stronger) segment, specifically, to the obstruent as in (30a,b) or a substituted obstruent as in (30c) (cf. among others, for English Barlow, 1997; Gnanadesikan, 1996, Ohala, 1996; for Dutch, Fikkert, 1994, Lohuis-Weber \& Zonnefeld, 1996; for German, Grijzenhout \& Joppen, 1998; for Greek, Drachman, 1973a; Kappa, 1999; Tzakosta, 2001; to appear).

$\begin{array}{llllll} & & \text { Target word } & \text { Child's output } & \text { Gloss } & \text { Age } \\ \text { a. } & \text { Stop + Sonorant: } & \text { 'kleo } & \text { 'keo } & \text { '(I) cry' } & 2 ; 2 \\ \text { b. Fricative + Sonorant: } & \text { 'vreçi } & \text { 'veçi } & \text { '(it) rains' } & 2 ; 9,7 \\ \text { c. } & \text { Fricative + Sonorant: } & \text { 'vreçi } & \text { 'beki } & \text { '(it) rains' } & 2 ; 2,20\end{array}$

The realization of the obstruent part of the cluster results in an unmarked syllable with a maximum rise in sonority slope toward the vowel (Clements, 1990). Although reduction to the less sonorous segment seems to be the most common pattern, reduction to the more sonorous segment has been attested in Spanish (Lleó \& Prinz, 1996). This reduction creates relatively more marked syllable shapes in comparison with those containing an obstruent segment. At stage I the deletion of the entire cluster yields a highly marked syllable shape, i.e. a vowel-initial syllable. According to Greenlee (1974) most children pass through the first stage; however it seems that it is not a widespread stage, because the other literature provides no evidence. This first stage is not attested in our data, instead our data in (31) cover only the stage II (ages 1;10-2;10).

(31) Reduction to the less sonorous segment

$$
\text { Target word Child's output Age Gloss }
$$

$\begin{array}{clll}\text { [Stop + Sonorant]: } & \text { [Sтор] } & & \\ \text { 'kleo } & \text { 'ceo } & 2 ; 2 & \text { 'cry', 1sG } \\ \text { 'krima } & \text { 'cima } & 2 ; 2,28 & \text { '(it's a) pity!' } \\ \text { 'plini } & \text { 'pini } & 2 ; 5,9 & \text { 'wash', 3sG } \\ \text { pro'i } & \text { po'i } & 2 ; 3,25 & \text { 'morning' } \\ \text { 'bluza } & \text { 'buna } & 2 ; 5,9 & \text { 'blouse' } \\ \text { o'brela } & \text { 'bela } & 2 ; 2,20 & \text { 'umbrella' } \\ \text { 'treno } & \text { 'teno } & 2 ; 3,18 & \text { 'train' } \\ \text { [Fricative + SonoRANT]: } & \text { [Stop] } & & \\ \text { 'vlaka } & \text { 'baka } & 2 ; 2 & \text { 'fool', ACC.SG }\end{array}$




\begin{tabular}{|c|c|c|c|}
\hline 'vreçi & 'beci & $2 ; 2,20$ & '(it) rains' \\
\hline 'vreçi & 'beçi & $2 ; 5,23$ & '(it) rains' \\
\hline 'fruto & 'puto & $2 ; 5,9$ & 'fruit' \\
\hline 'yrafo & 'bako & $2 ; 3,18 / 2 ; 4,11$ & '(I) write' \\
\hline but 'yrafo & $\begin{array}{l}\text { 'baxo } \\
\text { [FrIC] }\end{array}$ & $2 ; 6$ & '(I) write' \\
\hline 'fruto & 'futo & $2 ; 9$ & 'fruit' \\
\hline 'vlaka & 'vaka & $2 ; 9,7$ & 'fool', ACc.sG \\
\hline 'vreçi & 'veçi & $2 ; 9,7$ & '(it) rains' \\
\hline ' $\gamma$ rafi & 'vaçi & $2 ; 9,13$ & 'write', 3sG \\
\hline [STOP + FRICATIVE]: & {$\left[\mathrm{STOP}_{\mathrm{T}}\right]$} & & \\
\hline 'ksilo & 'cilo & $2 ; 2,20 / 2 ; 5,9$ & 'wood' \\
\hline psi'psina & pi'pina & $2 ; 9,13$ & 'pussycat' \\
\hline 'et ${ }^{s i}$ & 'eti & $2 ; 0 / 2 ; 6$ & 'so’' \\
\hline [Fricative + Stop]: & {$[\mathrm{STOP}]$} & & \\
\hline 'skilo & 'cilo & $2 ; 2,28 / 2 ; 9,13$ & 'dog', ACC.sG \\
\hline 'skala & 'kala & $2 ; 5,9 / 2 ; 9,13$ & 'stairs' \\
\hline 'spiti & 'piti & $2 ; 2 / 2 ; 9,13$ & 'house' \\
\hline 'asto & 'ato & $2,2,28$ & 'leave it! \\
\hline 'fusta & 'puta & $2 ; 5,23$ & 'skirt' \\
\hline le'fta & ta'ta & $2 ; 2$ & 'money' \\
\hline 'ftani & 'tani & $2 ; 4,18$ & '(it's) enough' \\
\hline 'xteni & 'teni & $2 ; 4,18$ & 'comb' \\
\hline xtes & tes & $2 ; 9,13 / 2 ; 10,2$ & 'yesterday' \\
\hline $\begin{array}{c}{[\text { FRICATIVE + FrICATIVE }]:} \\
\text { SXo'lio }\end{array}$ & $\begin{array}{l}{\left[\mathrm{STOP}_{\mathrm{TO}}\right]} \\
\text { ci'cio }\end{array}$ & $2 ; 5,23$ & 'school' \\
\hline $\begin{array}{r}{[\text { FRIC. }+ \text { STOP }+ \text { SONOR }]:} \\
\text { kre'mastra }\end{array}$ & $\begin{array}{l}\text { [STOP] } \\
\text { 'mata }\end{array}$ & $2 ; 4,11$ & 'clotheshanger' \\
\hline
\end{tabular}

The above data in (31) show that the child prefers the core syllable template, i.e. prefers less marked onsets than the complex ones. I assume that the child's inputs are adult-like (see, Section 1.2), i.e. her inputs contain the phonemes of the adult spoken forms. Since in OT the constraints are on the output, the inputs are free to contain all the segments Sofia hears. In limiting output onsets to one segment Sofia's grammar displays less markedness that the target language. In (32) we list certain markedness and faithfulness constraints that operate on output structures.

(32) Constraints

${ }^{\star}$ Complex $\quad$ No onset clusters (Prince \& Smolensky, 1993)

$\operatorname{Max}(\mathrm{I}-\mathrm{O}) \quad$ Every segment in the input has a correspondent in the output ('No deletion', McCarthy \& Prince, 1995) 
${ }^{*}$ M/Sonorant A sonorant must not be parsed as a syllable margin (adapted from Prince \& Smolensky, 1993).

${ }^{*}$ M/Oвstruent An obstruent must not be parsed as a syllable margin (adapted from Prince \& Smolensky, 1993).

DeP(I-O) Every segment in output the has a correspondent in the input ('No epenthesis', McCarthy \& Prince, 1995).

*[cont] Continuant obstruents are prohibited.

OCP No adjacent instances for particular features, e.g. [ ${ }^{\star} \alpha$ Place, $\alpha$ Place] (McCarthy 1986, Yip, 1988).

Ident [PLACE] If an input segment has the feature [ $\alpha$ Place], then its output correspondent has to be $[\alpha$ PLACE $]$ (McCarthy \& Prince, 1995).

IDENT[voice] If an input segment has the feature $[\alpha$ VoICE], then its output correspondent has to be $[\alpha$ VoICE $]$.

IDENT[CONT] If AN INPUT SEgment has The FEATURe [ $\alpha$ Continuant $]$, then its output correspondent has to be [aConTINUANT]

\subsubsection{The realization of target [STOP + SONORANT] clusters}

The unmarked structure of Sofia's onsets is the result of ranking the markedness ${ }^{*}$ CoMPLEx (which forbids complex onsets) highly, above the $\operatorname{Max}(\mathrm{I}-\mathrm{O})$ and $\operatorname{Dep}(\mathrm{I}-\mathrm{O})$ constraints, i.e. ${ }^{*}$ Complex $~ \operatorname{Max}(\mathrm{I}-\mathrm{O}),{ }^{*}$ Complex $»$ $\operatorname{DeP}(\mathrm{I}-\mathrm{O})$, (generally the constraint ${ }^{*}$ CoMpLEX above all faithfulness [FAITH] constraints), where the input and output segments are related by a mapping from the one to the other. Where the mapping does not describe identity between input and output, violations occur. MAx is violated by deletion, since deletion would result in a segment in the input that corresponds to no segment in the output. In adult speech the contrary happens. The constraint ${ }^{*}$ CoMPLEX is dominated and Greek ranks the Faith constraints above ${ }^{\star}$ Complex, so Sofia would not postulate the constraint ${ }^{\star}$ COMPLEX as a property of her target language. Sofia sometimes uses epenthesis as a strategy for cluster simplification (33); however epenthesis does not exhibit such a strong tendency as cluster reduction (cf. also Drachman, 1978:139, Fn.21; Kappa, 1999; Tzakosta, to appear). Epenthesis seems to be rare, specially for target /s/+Consonant clusters (Barlow \& Dinnsen, 1998), although it is attested in Dutch (Fikkert, 1994). Our Greek data provide no evidence for an epenthesis in /s/+Consonant clusters. In (33) follows an example of epenthesis in Greek in a [STOP + Sonorant] cluster.

$\begin{array}{lllll} & \text { Target word } & \text { Child's output } & \text { Age } & \text { Gloss } \\ {[\text { Stop + Sonorant }]:} & \text { 'ble } & \text { be'le } & 2 ; 2 & \text { 'blue'. } \\ & \text { 'bluza } & \text { be'lula } & 2 ; 5,9 & \text { 'blouse' }\end{array}$


In the above examples in (33) it is obvious that the child's syllable template cannot yet accommodate two consonants in the onset position, one of the two consonants does not fit into the template. The only way to realise the liquid is to make it an onset on its own. Since syllables have to have a head, epenthesis is the result. Such an analysis is given in Itô (1986) for epenthesis in adult languages. Remarkably, epenthesis in Sofia's productions occurs only during a short period. As an epenthetic vowel, Sofia uses the vowel [e], which is the default vowel for Greek (cf. Malikouti-Drachman \& Drachman (1988). The markedness constraint ${ }^{\star}$ CoMPLEx disallows consonant clusters in favor of less marked syllable structures. The faithfulness constraint DEP on the other hand prohibits epenthesis. Thus ${ }^{\star}$ COMPLEX and DEP are in conflict with one another. Because consonant clusters never occur in this child's productions at this phonological stage (up to the age of 3 years), we argue that the constraint ${ }^{*}$ Complex is undominated, therefore $\operatorname{Dep}(\mathrm{I}-\mathrm{O})$ must be ranked lower, i.e. ${ }^{*}$ Complex $» \operatorname{Dep}(\mathrm{I}-\mathrm{O})$. In the following tableau the candidate (a) violates the undominated ${ }^{\star}$ Complex constraint, therefore is not selected as the optimal output. Epenthesis as a strategy violates $\operatorname{DeP}(\mathrm{I}-\mathrm{O})$ but satisfies the undominated ${ }^{\star}$ Complex, therefore the candidate (b) is chosen the optimal output.

Adult form: ['bluza] $\rightarrow$ [be'lula] 'blouse', 2;5,9

\begin{tabular}{|l||c|c|}
\hline 'bluza & ${ }^{*}$ Complex & $\operatorname{Dep}(\mathrm{I}-\mathrm{O})$ \\
\hline \hline a. $\quad[$ 'bluza] & ${ }^{*}$ ! & $\checkmark$ \\
b. $\leftrightarrow$ [be'lula] & $\checkmark$ & $\star$ \\
\hline
\end{tabular}

Regarding the ranking between the constraints Max(I-O) and Dep(I-O), we assume that for a short period, both constraints are hierarchically equal, i.e. they are not ranked with respect to one another $\left({ }^{\star}\right.$ CoMplEX » MAX, DEP), allowing either deletion or epenthesis. Then, across all phonological stages, DeP dominates $\operatorname{MAx}(\mathrm{I}-\mathrm{O})$ and prevents epenthesis ( ${ }^{\star}$ CoMplex $»$ DeP » MAX). In (34) we repeate the data of $[$ STOP + SONORANT $]$ target clusters.

\begin{tabular}{|c|c|c|c|}
\hline $\begin{array}{r}\text { Target word } \\
{\left[\text { STOP }^{+} \text {SonORANT }\right]:}\end{array}$ & $\begin{array}{l}\text { Child's output } \\
\text { [STOP] }\end{array}$ & Age & Gloss \\
\hline 'kleo & 'ceo & $2 ; 2$ & 'cry', 1sG \\
\hline 'krima & 'cima & $2 ; 2,28$ & '(it’s a) pity !’ \\
\hline 'plini & 'pini & $2 ; 5,9$ & 'wash', 3sg \\
\hline pro'i & po'i & $2 ; 3,25$ & 'morning' \\
\hline 'bluza & 'buna & $2 ; 5,9$ & 'blouse' \\
\hline
\end{tabular}




$\begin{array}{lll}\text { o'brela } & \text { 'bela } & 2 ; 2,20 \\ \text { 'treno } & \text { 'teno } & 2 ; 3,18 \text { 'train' }\end{array}$

In the case of cluster reduction, the undominated constraint ${ }^{\star}$ CoMPLEX is in conflict with Max that prohibits deletion of the input segments. ${ }^{*}$ Complex dominates MAX and violation of MAx results in an unmarked CV-structure. In the tableaux (35) candidate (35a) incurs a violation of the constraint ${ }^{\star} \mathrm{CoM}$ PLEX, as the cluster [tr-] is present. Candidate (35b) does not violate ${ }^{\star}$ CoMPLEX because only one single consonant occurs in onset position. (35b) however, violates Max because the input $/ \mathrm{r} /$ is not parsed in the output form. This violation of MAx is less serious, because MAx is ranked lower than ${ }^{\star}$ CoMPLEx. The violation of ${ }^{\star}$ CoMPLEx by candidate $(35 a)$ is thus considered as fatal.

(35) Adult form: ['treno] $\rightarrow$ ['teno] 'train', 2;3,18

\begin{tabular}{|c||c|c|}
\hline 'treno & ${ }^{*}$ CoMPLEx & $\operatorname{Max}(\mathrm{I}-\mathrm{O})$ \\
\hline \hline a. $\quad[$ 'treno $]$ & $\star !$ & $\checkmark$ \\
b. $[$ 'teno $]$ & $\checkmark$ & $\star$ \\
\hline
\end{tabular}

Another issue is, why the child reduces a sonorant in favour of the plosive. We could explain that as a preference to the least sonorous initial onset or as a preference to the strongest consonant, i.e. to the plosive (cf. Drachman 1973a; Kappa 1999; Tzakosta 2001). Universally a sonorant is more sonorous than a fricative and a fricative is more sonorous than a plosive (36), or a plosive is stronger than a fricative, which is stronger than a sonorant

(36) Sonorant » Fricative » Plosive (»: more sonorous than)

Prince \& Smolensky (1993) proposed a family of markedness constraints based on the universal sonority hierarchy, known as ${ }^{\star} \mathrm{M} / \lambda$, defined in (37).

(37) ${ }^{\star} \mathrm{M} / \mathrm{\lambda}$ : $\lambda$ must not be parsed as a syllable margin (i.e. onset or coda)

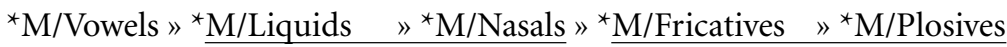
${ }^{\star} \mathrm{M} /$ Sonorants $\quad{ }^{*} \mathrm{M} /$ Obstruents

The above (abbreviated) Margin Hierarchy would disfavour the parsing of vowels into onset or coda position. Violation of such a constraint as ${ }^{\star} \mathrm{M} / \mathrm{a}$ (parse the vowel /a/ in onset/coda) is much more serious than a violation of ${ }^{\star} \mathrm{M} / \mathrm{k}$ (parse the plosive $/ \mathrm{k} /$ ). The plosive would surface as the more optimal onset/coda. Due to the universal Sonority hierarchy ${ }^{\star} M /$ Sonorant dominates ${ }^{\star} \mathrm{M}$ /Obstruent. A tentative constraint ranking thus far is given in (38). In the tableau with the constraint interaction for the target word /'treno/, the candidate 
(b) being a sonorant is ruled out and the candidate (a) being an obstruent, and violating the lower ranked constraint ${ }^{\star} \mathrm{M} /$ OвSTRUent, is selected as the optimal onset. The constraints Ident [PLAce], Ident[voice] and Ident[cont.] are not mentioned, because they are not relevant for the selection of optimal output in this case.

${ }^{*}$ CompleX $»$ MaX $»{ }^{*}$ M/Sonorant $»{ }^{*}$ M/Obstruent Adult form: ['treno] $\rightarrow$ ['teno] 'train', 2;3,18

\begin{tabular}{|r||c|c|c|c|}
\hline 'treno & ${ }^{*}$ Complex & Max & ${ }^{*}$ M/Sonorant & ${ }^{\star}$ M/ObSTRUENT \\
\hline \hline a. 'teno & $\checkmark$ & $*$ & $\checkmark$ & $\star$ \\
b. 'reno & $\checkmark$ & $*$ & $\star$ & $\checkmark$ \\
\hline
\end{tabular}

3.2.2 The realization of target [FRICATIVE + SONORANT] clusters In (39) we repeate the data of target [Fricative + SonORANT] clusters and their realizations with a substitute STOP (developmental sTAGE I in the acquisition of fricatives, cf. Kappa, 2000).

$\begin{array}{lllll} & \text { Target word } & \text { Child's output } & \text { Age } & \text { Gloss } \\ \text { [Fricative }+ \text { Sonorant] } & \text { [Stop] } & & \\ \text { a. } & \text { 'vlaka } & \text { 'baka } & 2 ; 2 & \text { 'fool', ACC.sG } \\ \text { b. } & \text { 'vreçi } & \text { 'beki } & 2 ; 2,20 & \text { '(it) rains' } \\ \text { c. } & \text { 'yrafo } & \text { 'bako } & 2 ; 3,18 / 2 ; 4,11 & \text { '(I) write' }\end{array}$

In (40) we establish the complete constraint ranking that operates on output structures of the target forms in (39) covers the reduction to a less sonorant segment.

$$
\begin{aligned}
& { }^{\star} \text { Comp » MaX » Ident }[\mathrm{PL}] » \operatorname{Ident}[\text { voi }] »{ }^{\star M} / \text { Son» }{ }^{\star}[\text { cont. }] » \\
& \text { IDENT }[\text { cont }] »{ }^{\star} \mathrm{M} / \text { OвS }
\end{aligned}
$$

We justify the constraint ranking in (40) describing the selection of the optimal less sonorous output in tableau (41). ${ }^{\star}$ CompLEx is unviolated in Sofia's speech, thus it must be considered undominated. (For the sake of simplification and due to space limits we do not mention the constraint IDENT [cont] in (41). The constraint is lower ranked, therefore always violated at this developmental stage and plays no role in the selection of optimal output). 
(41) [Fricative + Sonorant $] \rightarrow$ Stop (/'vlaka/ $\rightarrow$ ['baka] 'fool', 2;2)

\begin{tabular}{|lc||c|c|c|c|c|c|}
\hline & 'vlaka & MAx & $\begin{array}{c}\text { IDENT } \\
\text { [PLACE] }\end{array}$ & $\begin{array}{c}\text { IDENT } \\
\text { [voice] }\end{array}$ & ${ }^{*}$ M/SONOR. & $*$ [cont] & ${ }^{*}$ M/OBSTR. \\
\hline \hline a. & 'vaka & $*$ & $\checkmark$ & $\checkmark$ & $\checkmark$ & $*$ & $*$ \\
b. $\quad$ 'laka & $*$ & $\checkmark$ & $\checkmark$ & $\star$ & $\checkmark$ & $\checkmark$ \\
c. 'baka & $*$ & $\checkmark$ & $\checkmark$ & $\checkmark$ & $\checkmark$ & $*$ \\
d. $\quad$ 'paka & $*$ & $\checkmark$ & $* !$ & $\checkmark$ & $\checkmark$ & $*$ \\
\hline
\end{tabular}

The outputs candidates (41a-d) violate Max, the faithfulness constraint on correspondence between input and output, in order to satisfy ${ }^{\star}$ CoMPLEX, thus unmarked CV-syllable structures are produced. Candidate (41b) being a sonorant onset [1] is ruled out, because it violates the high ranked ${ }^{\star} \mathrm{M} /$ SONORITY constraint. The constraints Ident[place] and the Ident [voice] do not play a crucial role in the selection of candidate (41b) as an optimal one. Candidates (41a,c,d) satisfy ${ }^{\star} \mathrm{M} /$ SonOrANT, as well as the IDENT[PLACE] constraint, because the input and the correspondent output onset segments are labials obstruents. The violation of ${ }^{*}$ [cont] prevents the continuant obstruent $[v]$ in (41a) from surfacing. On the contrary candidates (41c) and (41d) are realized as (labial) plosives and satisfy the ${ }^{\star}[$ cont $]$ constraint. The satisfaction or violation of IDENT[voice] constraint makes the decision for the winning candidate. Thus, candidate (41c), being a voiced [b], thus faithful to the voiced input, is the winning candidate. Candidate (41d), being a voiceless [p], violates the IDENT[voice] and is ruled out. The above example in (41) covers not only the reduction to a less sonorant segment, but also justifies the realization of a plosive instead of a fricative as an optimal output. This is a case of emergent unmarkedness, i.e. a marked input (the fricative $/ \mathrm{v} /$ ) surfaces as an unmarked output (the plosive [b]) due to the action of markedness constraint ${ }^{\star}$ [cont]. The emergence of the unmarked (McCarthy \& Prince 1994) arises in such cases as a result of indeterminacy in candidate selection, thereby requiring low ranked markedness constraints to come into play. For the most part, these markedness are so low ranked that their effects are not generally apparent in the output. In instances of emergence of the unmarked, however, lower ranked constraints do have consequences for the harmonic output, requiring specifically that unmarked forms surface. In such cases as the example (41), the lower ranked markedness constraint ${ }^{*}$ [cont] also plays a significant role in the selection of the optimal output candidate, because fricatives do not occur at this stage. Therefore in such cases of cluster reduction 'emerges' as optimal output the most unmarked among the obstruents, i.e. a non-continuant segment. 
The example ['yrafo] $\rightarrow$ ['bako] '(I) write' in (39c) is a clear case not only of a sonority driven cluster reduction, but also of metathesis due to the highlyranked Align(Labial-left) constraint (cf. the single onsets, Section 3.1, the cases in (24), as well as (42b) and (45d) this section). In a word which has obstruents with more than one place of articulation, the child 'favours' to produce the obstruents in a front to back order (labials as left as possible). The constraint interaction of ALIGN(LABIAL-left) and * [cont] yields the optimal output in such cases as this example, where metathesis phenomena occur.

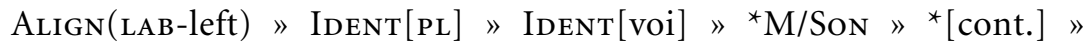
IDENT $\left[\right.$ cont $»{ }^{\star} \mathrm{M} /$ OBS

Our data provide evidence that when a cluster is reduced to a (less sonorous) fricative, then the realization of fricative will be carried out gradually, viz. it matches the course of realization of target fricatives as by the single onsets (cf. cases 21-24). The data in (42a) show, that after the cluster reduction, the word initial (target) fricatives are still realized as stops, although the word medial (target) fricatives are realized faithfully. We assume that this is a transition stage (III) in the realization of fricatives, where plosives are still favoured as optimal segments in word-initial position (42a,b). Besides, the child favours the labials word-initially, therefore she uses also metathesis in order to confront words starting with another place of articulation, e.g. a dorsal one (42b). The child confronts the input forms in (42a) and (42b) exactly the same way as for the single onsets (cf. examples (21a) and (24a,b), respectively, Section 3.1).

$\begin{array}{lllll} & \text { Target word } & \text { Child's output } & \text { Gloss } & \text { Age } \\ \text { a. } & \text { 'vreçi } & \text { 'beçi } & \text { '(it) rains' } & 2 ; 5,23 \\ \text { b. } & \text { 'yrafo } & \text { 'baxo } & \text { '(I) write' } & 2 ; 6\end{array}$

We assume that for the examples ( $42 \mathrm{a}, \mathrm{b})$ the contextual markedness constraint word $^{*}$ [cont] is active and high-ranked, dominating the IDENT[cont] constraint and preventing the input (word-initial) fricative to surface faithfully. Besides, the highly-ranked ALIGN(LABIAL-left) specifies that the labial feature will appear as close to the left edge (onset) as possible, therefore it is highly ranked. The constraint Ident[voice] is also active, demanding that the input and the corresponding output segment have the same value for [voicing]. The constraint ${ }^{*}$ [cont] is demoted, dominated by the promoted IDENT [cont]. Metathesis violates the LINEARITY constraint, which must be ranked very low, but allows the child to avoid violations of IDENT[cont]. In (43) we establish the constraint 
ranking that evaluates the above forms in $(42) .\left({ }^{\star} \mathrm{M} /\right.$ Sonorant and ${ }^{*} \mathrm{M} / \mathrm{OB}-$ STRUENT constraints are non mentioned due to simplification).

(43) $\operatorname{Align}($ Lab-left $) » \operatorname{Ident}[$ voice $] » \operatorname{word}^{*}[$ cont $] » \operatorname{IdENT}[$ cont $] »{ }^{*}[$ cont $] »$ LINEAR

The constraint interaction of ALIGN(LABIAL-left) and ${ }_{\text {word }}{ }^{*}$ [cont] yields the optimal output in such cases as the examples (42b), where metathesis phenomena occur.

(44) Adult form: ['yrafo] $\rightarrow$ ['baxo] '(I) write', 2;6

\begin{tabular}{|lc||c|c|c|c|c|c|}
\hline & 'yrafo & $\begin{array}{c}\text { AligN } \\
\text { (LAB-left) }\end{array}$ & $\begin{array}{c}\text { Ident } \\
\text { [voice] }\end{array}$ & wd $^{*}$ [cont] & $\begin{array}{c}\text { IDENT } \\
\text { [cont] }\end{array}$ & $*$ cont & Linear \\
\hline \hline a. & ['yafo] & $*$ & $\checkmark$ & $*$ & $\checkmark$ & $* *$ & $\checkmark$ \\
b. & ['gafo] & $*$ & $\checkmark$ & $\checkmark$ & $*$ & $*$ & $\checkmark$ \\
c. & {$[$ ['vaxo] } & $\checkmark$ & $\checkmark$ & $*$ & $\checkmark$ & $* *$ & $*$ \\
d. & ['payo] & $\checkmark$ & $* !$ & $\checkmark$ & $*$ & $*$ & $*$ \\
e. & ['baxo] & $\checkmark$ & $\checkmark$ & $\checkmark$ & $*$ & $*$ & $*$ \\
\hline
\end{tabular}

The candidates $(44 a, b)$ are excluded as optimal outputs, because both have a dorsal segment as the most left onset and violate Align (LABIAL-left). The candidates (44c), (44d) and (44e) compete with one another, because due to metathesis all satisfy the highly ranked ALIGN(LABIAL-left). The candidate (44c) violates word $^{\star}$ [cont] constraint, that forbids fricatives at the beginning of the word. Both candidates (44d) and (44e) start with a plosive and satisfy word $^{*}$ [cont]. The decision for optimal output is made by the satisfaction of constraint IDEnT[voice]. The (onset) obstruent segments of candidate (44e), although metathesised, are faithful to the input voicing in both onset positions, thus satisfying the IDENT[voice]. Therefore (44e) is selected as the optimal candidate. The reverse happens to (44d), which is ruled out.

At a later developmental stage in the acquisition of fricatives (sTAGE IV, about the age of 2;6), the reduced (less sonorous) fricative emerge faithfully due to the promotion of faithfulness constraint IDENT[cont], that also blocks the effects of contextual markedness constraint word $^{\star}$ [cont]. This later constraint is demoted due to the promotion of faithfulness IDENT [cont], therefore the child manages to produce surface forms more faithful to their inputs, but still respecting the undominated ${ }^{\star}$ CoMpLEX constraint. This is one more piece of evidence for the description of phonological stages as a constraint reranking (46). We repeat the relevant data in (45). 


$\begin{array}{lllll} & \text { Target word } & \text { Child's output } & \text { Age } & \text { Gloss } \\ \text { a. } & \text { 'fruto } & \text { 'futo } & 2 ; 9 & \text { 'fruit' } \\ \text { b. } & \text { 'vreçi } & \text { 'veçi } & 2 ; 9,7 & \text { '(it) rains' } \\ \text { c. 'vlaka } & \text { 'vaka } & 2 ; 9,7 & \text { 'fool', ACC.sG } \\ \text { d. } & \text { ' } \gamma \text { rafi } & \text { 'vaçi } & 2 ; 9,13 & \text { 'write', 3sG }\end{array}$

In (46) we establish the new constraint ranking, due to the due to the promotion of IDENT [cont]. We do not mention the highly ranked ${ }^{\star}$ Complex and MAX constraints, because ${ }^{\star}$ Complex is undominated and MAX is always violated because of the cluster reduction.

(46) Constraint ranking

Ident $[$ Place $] » \operatorname{IdEnt}\left[\right.$ volc] $»{ }^{*}$ M/Sonor. » Ident [cont. $] » *[$ cont $] »$ ${ }^{*} \mathrm{M} / \mathrm{OBSTR}$

(47) Adult form: ['fruto] $\rightarrow$ ['futo] 2;9 'fruit'

\begin{tabular}{|lc||c|c|c|c|c|c|}
\hline & 'fruto & $\begin{array}{c}\text { IDENT } \\
\text { [PLACE] }\end{array}$ & $\begin{array}{c}\text { IDENT } \\
\text { [voice] }\end{array}$ & ${ }^{*}$ M/Son. & $\begin{array}{c}\text { IDENT } \\
\text { [cont.] }\end{array}$ & ${ }^{*}$ [cont] & ${ }^{*}$ M/OBSTR. \\
\hline \hline a. & ['futo] & $\checkmark$ & $\checkmark$ & $\checkmark$ & $\checkmark$ & $*$ & $*$ \\
b. & ['ruto] & $\checkmark$ & $\checkmark$ & $* !$ & $\checkmark$ & $\checkmark$ & $\checkmark$ \\
c. & ['puto] & $\checkmark$ & $\checkmark$ & $\checkmark$ & $\star !$ & $\checkmark$ & $*$ \\
d. & ['vuto] & $\checkmark$ & $\star$ & $\checkmark$ & $\checkmark$ & $*$ & $*$ \\
\hline
\end{tabular}

The tableau (47) illustrates how the selection of the optimal output is sonority driven and how the input fricative surfaces faithfully due to the promoted IDENT [cont]. All candidates (47a-d) satisfy the highly ranked constraint IdENt [Place]. Candidate (47b) being a sonorant $[\mathrm{r}]$ violates the high-ranked ${ }^{\star} \mathrm{M} /$ Sonorant constraint and is ruled out. Candidate (47c), being a plosive $[\mathrm{p}]$, violates the promoted IDENT [cont] constraint, therefore is also ruled out. Both candidates (47a) and (47d) being non-sonorant labial segments satisfy the highranked ${ }^{*} \mathrm{M} /$ Sonorant and the IDENT[cont] constraints. In this case the decision for the optimal output is made by the satisfaction of highly-ranked constraint IDENT[voice]. Candidate $(47 \mathrm{~d})$ surfacing as a voiced fricative [v] is not compatible with the input voiceless segment /f/, it violates the IDENT[voice] constraint and is ruled out. Candidate (47a) surfaces faithfully as voiceless fricative $[\mathrm{f}]$ and is chosen as the optimal output.

In the course of phonological development the constraint ALIGN(LABIAL-left) remains active and highly ranked for a long time (it is also attested by the age of $2 ; 9,13$, cf. the cases in $(24 \mathrm{~d}, \mathrm{e}))$. The case in $(45 \mathrm{~d})$ shows not only a sonority driven cluster reduction, but also a metathesis due to the highly-ranked 
Align(Labial-left) constraint (see analysis in (49)). In order to capture such cases with metathesis, we reformulate the constraint ranking established in (46) with addition of the highly-ranked constraint Align(Labial-left) (48).

(48) $\operatorname{Align}($ Labial-left) $) \operatorname{Ident}[$ voice $] » \operatorname{Ident}[$ cont $]$ » word ${ }^{*}[$ cont $] »{ }^{*}[$ cont $] »$ LINEARITY

There follows an example of the constraint interaction due to metathesis (49).

(49) Adult form: ['yrafi] $\rightarrow$ ['vaçi] '(she) writes' 2;9,13

\begin{tabular}{|c|c|c|c|c|c|c|}
\hline 'yrafi & $\begin{array}{c}\text { Align } \\
\text { (LAB-left) }\end{array}$ & $\begin{array}{l}\text { IDENT } \\
\text { [voice] }\end{array}$ & $\begin{array}{l}\text { IDENT } \\
\text { [cont] }\end{array}$ & $\mathrm{wd}^{*}[$ cont $]$ & ${ }^{*}$ cont & LINEARITY \\
\hline a. ['yafi] & * & $\checkmark$ & $\checkmark$ & * & $* *$ & $\checkmark$ \\
\hline b. ['gafi] & * & $\checkmark$ & * & $\checkmark$ & $\checkmark, *$ & $\checkmark$ \\
\hline c. ['vaçi] & $\checkmark$ & $\checkmark$ & $\checkmark$ & * & $* *$ & * \\
\hline d. ['baçi] & $\checkmark$ & $\checkmark$ & *! & $\checkmark$ & $\checkmark$ & * \\
\hline
\end{tabular}

The candidates $(49 \mathrm{a}, \mathrm{b})$ are excluded as optimal outputs, because both have a dorsal onset on the left and violate the still highly ranked Align(LABial-left). The candidates (49c) and (49d) compete with one another, because due to metathesis both satisfy the highly ranked ALIGn(LABIAL-left). The decision for the optimal output is made by satisfaction or violation of the faithfulness constraint IDENT [cont]. The candidate (49d,) being a plosive, incurs a violation of IDENT[cont], therefore wins the more faithful (fricative) candidate (49c), which incurs no violation of IDENT [cont].

There are certain apparent exceptions to the above reduction pattern of [Fricative + Sonorant] clusters. There are some clusters of this kind, that do not reduce to the less sonorous segment, i.e. to the fricative, although fricatives have been acquired by the child. In the following examples in (50) a reduction to the more sonorous segment occurs.

(50) Reduction to the more sonorous segment

$\begin{array}{llll}\text { Target word } & \text { Child's output } & \text { Age } & \text { Gloss } \\ \text { 'pavlo } & \text { 'palo } & 2 ; 4,11 / 2 ; 6 & \text { 'Paul' ACC } \\ \text { vi'vlio } & \text { bi'lio } & 2 ; 5,23 & \text { 'book' } \\ \text { vi'vlio } & \text { vi'lio } & 2 ; 9,13 & \text { 'book' } \\ \text { 'vlepo } & \text { 'lepo } & 2 ; 6 / 2 ; 9,20 & \text { '(I) see' } \\ \text { yli'ko } & \text { li'ko } & 2 ; 6,7 / 2 ; 9 & \text { 'sweet' } \\ \text { 'ylika } & \text { 'lika } & 2 ; 9,15 & \text { 'sweety' }\end{array}$


We argue that cluster reduction to the less sonorous is blocked if within the word there is another consonant bearing the same (specified) place of articulation with the less sonorous segment, as in (51).

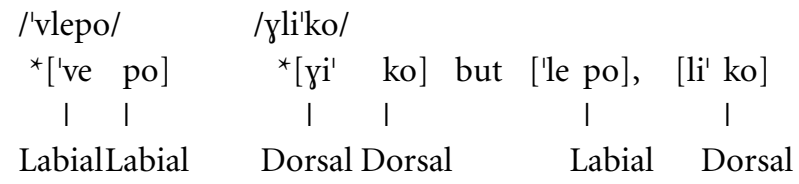

The above cases in (51) show a clear OCP effect. The OCP serves to prevent adjacent instances of particular features. In this case, the OCP prohibits adjacent instances of the place feature LABIAL or of the place feature DORSAL. ${ }^{27}$ The operation of OCP in child language is one more evidence that deletion is grammatical and is not due to a perceptual error. ${ }^{28}$ In the above cases in (50) the labial or dorsal segment of the cluster deletes to avoid violating the markedness constraint OCP. This is one more instance of the emergence of the unmarked in the child's productions (McCarthy \& Prince, 1994). A typical case of this is when demoted markedness constraints are activated in special situations, where the higher (ranked) faithfulness constraints are irrelevant. This results in unmarked structures which surface to satisfy these markedness constraints. The deletion of the dorsal or labial parts of the above clusters is due to the ranking of OCP in the constraint hierarchy. We reformulate the complete constraint hierarchy establishing the ranking of OCP as well, (52).

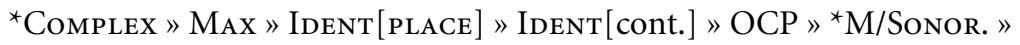

$$
\begin{aligned}
& \text { *[cont. }] »{ }^{\star} \mathrm{M} / \text { OвstR }
\end{aligned}
$$

In the above constraint ranking (52) the OCP is dominated by the higher ranked faithfulness constraints MAX and IDENT[PLACE], therefore OCP is frequently violated, as in tableau (53); the word [pa'pu] ('grandfather') has two adjacent Labial consonants. OCP has not always the power to prevent the surfacing of segments that are underlyingly specified, e.g. for place of articulation. In the case of the candidate in (53a) both labial consonants are alone in onset position and they must show up as labials despite the violation of OCP. The faithfulness constraints MAX and IDENT[PLACE] are dominant. A violation of $\mathrm{MAx}$ as in (53b, $\left.{ }^{*}[\mathrm{pa} . \mathrm{u}]\right)$ results in an onsetless syllable that is a highly marked one. We assume that the constraint OnSET ('all syllables must have onset') is also highly ranked in the child's phonology and forces a single initial consonant to show up. The satisfaction of MAx in connection with that of IDENT[PLACE] allows the output (53a) to be the optimal one. 
(53) Adult form: [pa'pu] $\rightarrow$ [pa.'pu] 'grandfather', MAsC.ACC.sG

\begin{tabular}{|c|c|c|c|c|c|c|c|c|}
\hline pa'pu & ${ }^{*}$ СомPL & $\operatorname{Max}$ & $\begin{array}{c}\text { IDENT } \\
{[\text { PLACE] }}\end{array}$ & $\begin{array}{l}\text { IDENT } \\
\text { [cont.] }\end{array}$ & $\begin{array}{l}\text { Ocp } \\
{[\mathrm{Lab}]}\end{array}$ & ${ }^{*} \mathrm{M} / \mathrm{SON}$ & ${ }^{*}$ [cont] & ${ }^{*} \mathrm{M} / \mathrm{oBs}$ \\
\hline $\begin{array}{l}\text { a. }[\text { pa.'pu] } \\
\text { b. }[\text { pa.'u] }\end{array}$ & s & $\begin{array}{l}5 \\
!\end{array}$ & 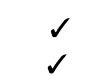 & 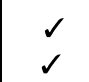 & * & $\checkmark$ & & \\
\hline
\end{tabular}

When there are more segments to choose from, there is a way of satisfying both IDENT[PLACE] and the OCP, as in tableau (54), candidate (54a). In such a case as the input form /vlepo/ there occurs deletion of the labial part of the cluster, i.e. the labial segment $[\mathrm{v}]$. If $[\mathrm{v}]$ is deleted, then the constraint IDENT $\left[\right.$ PLACE $\left._{\text {Labial }}\right]$ is irrelevant, since there is no output correspondent of [v] for labial to show up on. The IDENT constraint can not be violated by a segment that is not in the output. If the labial segment is deleted, then the highly ranked IDENT $\left[\right.$ PLACE $\left._{\text {Labial }}\right]$ constraint can be bypassed and the OCP is also satisfied. The deletion is the best option, although it violates MAx and results in reduction to a more sonorous segment. The more sonorous segment [l] surfaces violating on the one hand the ${ }^{\star} \mathrm{M} /$ SonORANT constraint but satisfying on the other hand the OCP. This is a case of emergent unmarkedness because a lower ranked markedness constraint (the OCP), the effects of which are usualy not evident, as in the above case of (53a), is preventing a less sonorous segment (the fricative [v], in (54b)) from occurring in target consonant clusters.

Adult form: ['vlepo] $\rightarrow$ ['lepo] ('I) see' 2;6/2;9,20

\begin{tabular}{|c||c|c|c|c|c|c|c|}
\hline 'vlepo & Max & $\begin{array}{c}\text { IDENT } \\
\text { [PLACE }]\end{array}$ & $\begin{array}{c}\text { IDENT } \\
{[\text { cont }]}\end{array}$ & $\begin{array}{c}\text { Ocp } \\
{[\text { Lab }]}\end{array}$ & ${ }^{*}$ M/Son & $*$ [cont] & M/OBs \\
\hline \hline $\begin{array}{l}\text { a. } \\
\text { b. ['lepo] }\end{array}$ & $*$ & $\checkmark$ & $\checkmark$ & $\checkmark$ & $*$ & $\checkmark$ & $\checkmark$ \\
['vepo] & $*$ & $\checkmark$ & $\checkmark$ & $* !$ & $\checkmark$ & $*$ & \\
\hline
\end{tabular}

In the last example (55) the same [Fricative + Sonorant] cluster [vl-] as above in (54) reduces to the less sonorous segment, i.e. to the fricative [v] in (55b). The OCP is not active because the obstruent consonants $[\mathrm{v}]$ and $[\mathrm{k}]$ differ in the place of articulation (/v/: Labial, $/ \mathrm{k} /$ : Dorsal). In this case the sonority constraint ${ }^{\star} \mathrm{M} / \mathrm{SonORANT}$ prescribes the optimal output (55b), i.e reduction to the less sonorous segment occurs. 
(55) Adult form: ['vlaka] $\rightarrow$ ['vaka] 'fool', Acc. Sg. 2;9,7

\begin{tabular}{|c|c|c|c|c|c|c|c|}
\hline 'vlaka & Max & $\begin{array}{l}\text { IDENT } \\
{[\text { PLACE] }}\end{array}$ & $\begin{array}{l}\text { IDENT } \\
\text { [cont.] }\end{array}$ & $\begin{array}{l}\text { OcP } \\
{[\mathrm{Lab}]}\end{array}$ & ${ }^{*} \mathrm{M} / \mathrm{SoN}$ & ${ }^{*}[$ cont $]$ & M/овл \\
\hline $\begin{array}{l}\text { a. ['laka] } \\
\text { b. ['vaka] }\end{array}$ & $\begin{array}{l}* \\
*\end{array}$ & $\begin{array}{l}1 \\
d\end{array}$ & $\begin{array}{l}2 \\
2\end{array}$ & $\begin{array}{l}4 \\
s\end{array}$ & $\stackrel{*}{\star} !$ & $\begin{array}{l}\checkmark \\
*\end{array}$ & $\checkmark$ \\
\hline
\end{tabular}

3.2.3 The realization of target [OBSTRUENT+OBSTRUENT] clusters In the cases of target words with [Овsтruent + Овstruent] clusters surfaces only a stop. In (56) we repeat the relevant data.

(56) [Obstruent + Obstruent] clusters

\begin{tabular}{|c|c|c|c|}
\hline Target word & Child's output & Age & Gloss \\
\hline [Stop + Fricative $]:$ & {$[\mathrm{S}$ тор $]$} & & \\
\hline 'ksilo & 'cilo & $2 ; 2,20 / 2 ; 5,9$ & 'wood' \\
\hline psi'psina & pi'pina & $2 ; 9,13$ & 'pussycat' \\
\hline 'et ${ }^{s} \mathrm{i}$ & 'eti & $2 ; 0 / 2 ; 6$ & 'so’’ \\
\hline [FRICATIVE + Stop]: & {$\left[\mathrm{STOP}_{\mathrm{T}}\right]$} & & \\
\hline 'skilo & 'cilo & $2 ; 2,28 / 2 ; 9,13$ & 'dog', ACC.sG \\
\hline 'skala & 'kala & $2 ; 5,9 / 2 ; 9,13$ & 'stairs' \\
\hline 'skupa & 'puka & $2 ; 8,17$ & 'broom' \\
\hline 'spiti & 'piti & $2 ; 2 / 2 ; 9,13$ & 'house' \\
\hline 'asto & 'ato & $2,2,28$ & 'leave it! \\
\hline 'fusta & 'puta & $2 ; 5,23$ & 'skirt' \\
\hline lefta & ta'ta & $2 ; 2$ & 'money' \\
\hline 'ftani & 'tani & $2 ; 4,18$ & '(it's) enough' \\
\hline 'xteni & 'teni & $2 ; 4,18$ & 'comb' \\
\hline xtes & tes & $2 ; 9,13 / 2 ; 10,2$ & 'yesterday' \\
\hline [Fricative + Fricative]: & {$[$ STOP $]$} & & \\
\hline sxo'lio & ci'cio & $2 ; 5,23$ & 'school' \\
\hline 'sfera & 'pela & $2 ; 4,18 / 2 ; 6$ & 'sphere' \\
\hline
\end{tabular}

The above examples are also cases of reduction to the less sonorous consonant, i.e. the stop. Within the natural class of obstruents, fricatives are universally more sonorous than stops $\left({ }^{\star} \mathrm{M} / \mathrm{FRICATIVE} »{ }^{\star} \mathrm{M} / \mathrm{STOP}\right)$. We assume that at this stage of phonological development the reduction is not only sonority-driven, but is also based on the selection of the least marked among the obstruents, i.e a non-continuant segment (stop). Therefore we assume that the selection of a stop is a form of emergent unmarkedness, due to the action of markedness 
constraint ${ }^{*}[$ cont $]$, whose effects are evident, even if is low ranked. In the tableau (57) the candidate (57a) violates the undominated ${ }^{\star}$ CompLex constraint, therefore is excluded as an optimal output. Both candidates $(57 b, c)$ satisfy ${ }^{\star}$ CoMPLEX, violating MAX. Both candidates satisfy IdENT[cont]; output candidate (57b) corresponds to the input continuant, while output candidate (57c) corresponds to the input non-continuant. The constraint ${ }^{*}$ [cont] decides for the winning candidate. Candidate (57b) being a continuant violates the constraint and is ruled out. Candidate (57c) being a non-continuant satisfies ${ }^{\star}$ [cont] and is selected as the optimal output, i.e. the effects of a low ranked constraint as ${ }^{\star}$ [cont] do have consequences for the harmonic output, requiring that unmarked forms surface. Therefore in cases of obstruents cluster reduction 'emerges' as optimal output the most unmarked among the obstruents, i.e. a non-continuant segment.

\begin{tabular}{|c|c|c|c|c|c|c|}
\hline 'ksilo & ${ }^{\star}$ Complex & Max & $\begin{array}{l}\text { IDENT } \\
\text { [cont] }\end{array}$ & ${ }^{*}[$ cont $]$ & ${ }^{*} \mathrm{M} / \mathrm{FRIC}$ & ${ }^{*} \mathrm{M} / \mathrm{STOP}$ \\
\hline a. ['ksilo] & * & $\checkmark$ & $\checkmark$ & $\checkmark$ & $\checkmark$ & * \\
\hline b. ['silo] & $\checkmark$ & * & $\checkmark$ & $* !$ & * & $\checkmark$ \\
\hline c. $\otimes$ ['cilo] & $\checkmark$ & * & $\checkmark$ & $\checkmark$ & $\checkmark$ & * \\
\hline
\end{tabular}

We would like to point out that the affricate $/ \mathrm{t}^{\mathrm{s}} /$ surfaces like the clusters /ps/ and $/ \mathrm{ks} / \mathrm{do}$, i.e. only the non-continuant part of the segment surfaces e.g. /'et $\mathrm{t}^{\mathrm{s}} \mathrm{i} /$ : ['eti] 'so'). The undominated constraint ${ }^{\star}$ Complex functions not only as a constraint against clusters but also against complex segments (cf. Kappa 1998a).

In case of target [Fricative + Fricative] clusters there occurs a reduction to the less sonorous (substituted) segment. In the class of fricatives, dorsals and labials are less sonorous than the coronal /s/ and this can be expressed with the constraint ranking ${ }^{\star} \mathrm{M} / \mathrm{CoRONAL} »{ }^{\star} \mathrm{M} /$ DorsaL, ${ }^{*} \mathrm{M} / \mathrm{LABIAL}$, where ${ }^{\star} \mathrm{M} / \mathrm{CoRO}-$ NAL dominates ${ }^{\star} \mathrm{M} /$ DorsaL and ${ }^{\star} \mathrm{M} / \mathrm{LABIAL}$, (cf. the sonority hierarchy given by Malikouti-Drachman 1984). We would expect that the above clusters would reduce to the less sonorant fricative, i.e. to the dorsal or to the labial one. But this is not the case. The clusters reduce to a (substituted) dorsal or labial plosive. According to the stages in the realization of fricatives for single onsets (given in Section 3.1), we predict that by these ages no (input) fricative will surface. At the early stages (cf. case 16) this may be attributed to action of highly ranked general markedness constraint ${ }^{\star}$ [cont], which dominates IDENT[cont]. At a later stage, when the constraint IDENT[cont] is promoted it may be 
attributed to action of highly ranked contextual markedness constraint ${ }_{\text {word }}{ }^{*}$ [cont], which obscures the action of the faithfulness constraint IDENT[cont] (cf. 21-23). The realization of the coronal or dorsal/labial part of the target cluster is attributed to the interaction of ${ }^{*}[$ cont $]$ and the lower ranked ${ }^{\star} \mathrm{M} / \mathrm{Co}$ RONAL» ${ }^{*} \mathrm{M} /$ DorSAL, ${ }^{\star} \mathrm{M} /$ LABIAL constraints. We predict, that the coronal fricative will be reduced and due to the high ranking of ${ }^{\star}[$ cont] there will surface the dorsal/labial non-continuant counterpart of the input fricative. This is again an instance of the emergence of the unmarked, where after a reduction in a target obstruent cluster [s+dorsal/labial FrIc.], there will surface an obstruent, which is not only the less sonorous but also the less marked with regard to continuancy, i.e a labial or dorsal plosive (cf. tableau in 58).

(58) Adult form: ['sfera] $\rightarrow$ ['pela] 2;4,18 'sphere'

\begin{tabular}{|c|c|c|c|c|c|c|c|}
\hline 'sfera & ${ }^{*}$ CoMPL & MAx & $\begin{array}{c}\text { IDENT } \\
{[\text { Place }]}\end{array}$ & ${ }^{*}[$ cont $]$ & $\begin{array}{l}\text { IDENT } \\
\text { [cont] }\end{array}$ & ${ }^{\star} \mathrm{M} / \mathrm{CoR}$ & ${ }^{*} \mathrm{M} / \mathrm{LAB}$ \\
\hline ['sfera] & * & $\checkmark$ & $\checkmark$ & ** & $\checkmark$ & * & $\checkmark$ \\
\hline ['sela] & $\checkmark$ & * & $\checkmark$ & * & $\checkmark$ & * & $\checkmark$ \\
\hline $\begin{array}{ll}\text { c. } & \text { 'fela] }\end{array}$ & $\checkmark$ & * & $\checkmark$ & * & $\checkmark$ & $\checkmark$ & * \\
\hline d. ['pela] & $\checkmark$ & * & $\checkmark$ & $\checkmark$ & * & $\checkmark$ & * \\
\hline e. ['tela] & $\checkmark$ & * & $\checkmark$ & $\checkmark$ & * & $* !$ & $\checkmark$ \\
\hline
\end{tabular}

In the tableau (58) the candidate (58a) violates the undominated ${ }^{\star}$ CompLEX constraint, therefore is excluded as an optimal output. All candidates (58b-e) satisfy ${ }^{\star}$ Complex, violating Max. All candidates satisfy Ident [PlaCet]; output candidates (58b) and (58e) being coronals correspond to the coronal feature of input segment $/ \mathrm{s} /$, while output candidates $(58 \mathrm{c})$ and $(58 \mathrm{~d})$ correspond to the labial feature of the input segment /f/. Candidates $(58 \mathrm{~b}, 58 \mathrm{c}$ ) being continuants violate the highly ranked ${ }^{\star}[$ cont] therefore both are ruled out. Besides, candidates (58d) and (58d), surfacing as non-continuants, satisfy * [cont]. The really competing candidates now are (58d) and (58e). Candidate (58e) surfacing as coronal $\left[\mathrm{t}\right.$ ] violates the higher ranked ${ }^{\star} \mathrm{M} / \mathrm{CononaL}$ and is ruled out, while candidate (58d) surfacing as labial [p] satisfies the ${ }^{\star} \mathrm{M} /$ CoronAL and is selected as the optimal output. The violation of the lowest ranked ${ }^{\star} M / L A B I A L$ plays no role in the selection of the optimal candidate. The effects of a low ranked constraint as ${ }^{\star} \mathrm{M} /$ Coronal do have consequences for the harmonic output, requiring that unmarked forms surface. Therefore in cases of obstruent clusters reduction 'emerges' as optimal output the most unmarked among the obstruents, i.e. a non-continuant segment.

We predict that in case of target [OBstruent + OBstruent + SonORANT] clusters, the child will produce only a [STOP] as above in (57) or (58), i.e. the 
sonorant will be reduced due to the action of highly ranked ${ }^{\star} \mathrm{M} /$ SONORANT and the fricative will be ruled out due to the action of ${ }^{\star}$ [cont]. We have attested only the following example, in (59).

(59) Adult form: [kre'mastra] $\rightarrow$ ['mata] 2;4,11 'clotheshanger'

\subsection{The realization of (target) Codas}

In the previous sections $(3.1,3.2)$ we presented some evidence that the child's phonology consists of core syllables. In the present section we focus on developmental stages in the acquisition of codas. More evidence will be given in support of the hypothesis that in the initial stages of acquisition the child does not produce forms with final consonants, i.e. only open syllables. It has been reported in the acquisition literature that such a stage without codas is common (cf. Fikkert 1994, for Dutch; Fee 1995, for English; Grijzenhout \& Joppen 1998, for German; Kappa 2002, for Greek). ${ }^{29}$

Codas are cross-linguistically marked constituents. It has been proposed in the literature on child phonology that children's first final consonants are not codas. Instead they are syllabified as onsets of empty headed syllables (cf. Goad 1998). On this view, augmentation of CVC words to CVCV at the earliest stages in acquisition is motivated solely by the desire to avoid codas. This is counter to the hypothesis put forward in Fee (1992), that augmentation is driven by word minimality, the idea that words must minimally contain one foot. However the data from early child language in Greek show that augmentation of CVC words is avoided. Instead deletion of the final coda consonants is preferred, which contradicts the above mentioned claims. The deletion of final codas in the CVC, CVCVC forms are shown in $(60 \mathrm{a}, \mathrm{b})$. The deletion of medial codas in the CVCCV forms are shown in (61). It has to be mentioned that the medial codas of the target words are not realized in the child's output until a very late stage of phonological development (about the age of 3;5).

(60) Final Codas Stage I. (ages 1;10-2;2)

$\begin{array}{lllll}\text { a. } & \text { Monosyllabic inputs } & \text { Child's ouput } & \text { Age } & \text { Gloss } \\ \text { fos } & \text { po } & 2 ; 0 & \text { 'light', NOM.sG } \\ \text { bes } & \text { be } & 2 ; 0,7 & \text { 'come in', 2.IMP } \\ \text { b. } & \text { Multisyllabic inputs } & \text { Child's output } & \text { Age } & \text { Gloss } \\ \text { 'sakis } & \text { 'kaki } & 1 ; 11 & \text { 'proper name' NOM } \\ \text { ba'bas } & \text { ba'ba } & 1 ; 10 & \text { 'daddy', NOM.sG } \\ \text { kal'tson } & \text { to'to } & 1 ; 11,7 & \text { 'tights' } \\ \text { bu'fan } & \text { bo'pa } & 2 ; 2 & \text { 'anorak' }\end{array}$




$\begin{array}{lll}\text { Medial Codas } & & \\ \text { 'volta } & \text { 'bota } & 2 ; 2 / 2 ; 4,11 \text { 'walk' } \\ \text { 'olya } & \text { 'oga } & 2 ; 3,18 \text { 'proper name', NOM } \\ \text { 'olya } & \text { 'opa } & 2 ; 9,13 \text { 'proper name', NOM } \\ \text { 'parti } & \text { 'pati } & 2 ; 2,28 / 2 ; 10 \text { 'party' } \\ \text { 'marko } & \text { 'mako } & 2 ; 2 \quad \text { 'proper name', ACC }\end{array}$

Given that in Greek the trochaic foot is the default pattern (cf. MalikoutiDrachman \& Drachman 1989; Malikouti-Drachman 1999) which seems to be the minimal prosodic word in Greek child language (cf. Kappa 1998b; to appear), one is led to expect that the child would produce the forms in (60a) as augmented outputs, i.e. disyllabic forms. The final /s/ of the above adult forms in $(60 \mathrm{a}, \mathrm{b})$ carries also morphological information, i.e. it is part of a morphological marker, e.g. for gender/case [fos] : neutral, NOM.sG, [ba'bas] MAsc.NOM.sG. cf. [ba'ba] MASC.ACC.sG) or $/ \mathrm{s} /$ is a marker for person in the verbs, e.g. [bes] 2sG.Imp.). This morphological information is not evident in this stage. The deletion of the final coda consonants $/ \mathrm{s} /$ and $/ \mathrm{n} /$ indicates that in the initial stage of acquisition the child produces only the unmarked CV syllable shapes.

The deletion of medial and final codas indicates that the prosodic markedness constraint NoCoda is highly ranked in the child's phonology, above the constraint of FоотBinarity (FtBin: 'Feet must be binary', cf. Prince 1980) and the correspondence constraint Anchoring-IO(GrWd, R) (cf. McCarthy \& Prince 1995). The ANCHORING-IO constraint demands that any segment at the right periphery of the output grammatical word $(\mathrm{GrWd})$ has a correspondent at the right periphery of the input (GrWd) and its function is to block deletion or epenthesis at the edge of a grammatical word. Besides, the faithfulness constraint IDENT [cont] is low ranked, so that its effects are not evident. Thus in the case of monosyllabic words as in (60a), the child produces on the one hand an unmarked CV-syllable (cf. tableau in (62), candidate (b)), but on the other hand a monosyllabic prosodic and grammatical word that violates, FootBinarity, Anchoring-IO(GrWd, R) and Ident[cont. In spite of these violations the output candidate (62b) is more optimal than candidate (62a), because (62b) satisfies the undominated NoCoDA constraint. 
(62) Adult form: [bes] $\rightarrow$ [be] 2;0,7 'come in', 2.IMP

\begin{tabular}{|c||c|c|c|c|c|}
\hline bes & NoCodA & Max(I-O) & FtBin & $\begin{array}{c}\text { AnChOR-IO } \\
\text { (GrWd, R })\end{array}$ & $\begin{array}{c}\text { IDent } \\
\text { [cont }]\end{array}$ \\
\hline \hline $\begin{array}{l}\text { a. }[\text { bes] } \\
\text { b. [be] }\end{array}$ & $\star$ & $\checkmark$ & $*$ & $\checkmark$ & $\checkmark$ \\
\end{tabular}

In the case of disyllabic words in $(60 \mathrm{~b}, 61)$, the child produces on the one hand unmarked CV-syllable shapes and satisfies FоotBinarity, but on the other hand violates the $\operatorname{Max}(\mathrm{I}-\mathrm{O})$ constraint due to the deletion of the word final segment. Therefore the prosodic word does not correspond with the grammatical word violating the ANCHORING-IO(GRWD, R) constraint (candidate 63b, in the tableau in 63). In this case the dominating NoCodA constraint is the determinant for the optimal output and its violation prevents the candidate (63a) from being the optimal one, although this candidate satisfies all lower ranked constraints. The candidate (63b) satisfies the undominated NoCodA and it is the optimal output at the stage I.

(63) Adult form: [ba'bas] $\rightarrow$ [ba'ba] 1;10 'daddy', NOM.sG

\begin{tabular}{|c|c|c|c|c|c|}
\hline ba'bas & NoCoda & $\operatorname{Max}(\mathrm{I}-\mathrm{O})$ & FTBIN & $\begin{array}{c}\text { ANCHOR-IO } \\
(\text { GrWd, R) }\end{array}$ & $\begin{array}{l}\text { IDENT } \\
\text { [cont] }\end{array}$ \\
\hline $\begin{array}{l}\text { a. } \quad\left[\mathrm{ba} \mathrm{b}^{\mathrm{b} a s}\right] \\
\text { b. }[\mathrm{ba} \text { 'ba }]\end{array}$ & * & $\begin{array}{l}6 \\
*\end{array}$ & $\begin{array}{l}1 \\
d\end{array}$ & $\begin{array}{l}\mathcal{J} \\
*\end{array}$ & $\begin{array}{l}\mathcal{J} \\
*\end{array}$ \\
\hline
\end{tabular}

The word-medial codas in the tableau (64) are also not realized due to the undominated NoCoda constraint and they develop much later than the final codas. Our data show no medial codas, even when medial onset clusters surface. When medial codas are realized, they have additional constraints on them (Bernhardt \& Stemberger, 1998).

(64) Adult form: ['volta] $\rightarrow$ ['bota] 2;2/2;4,11 'walk'

\begin{tabular}{|c||c|c|}
\hline \multicolumn{1}{|c||}{ 'volta } & NoCodA & $\operatorname{MAx}(\mathrm{I}-\mathrm{O})$ \\
\hline \hline a. $\quad[$ ['vol.ta] & $*$ & $\checkmark$ \\
b. $[$ ['bo.ta] & $\checkmark$ & $*$ \\
\hline
\end{tabular}

At a subsequent stage of phonological development (STAGE II for codas, after the age of $2 ; 2,20$ ) a final coda consonant is allowed. At this stage, $83 \%$ of the output forms are realized with a final coda, whereas $17 \%$ of the output forms are still realized as in STAGE I, with no coda final segment. The medial codas are still not realized. The data in (65) show the realization of the place/manner 
features of the input final segments /s/ and /n/. The child realizes the continuant manner feature and the unmarked coronal place feature of the input final consonant. At this stage a manner contrast will be introduced by the occurrence of the fricative $[s]$ in the context of word-final position (STAGE I in the acquisition of fricatives).

(65) Final Codas Stage II.

a. Monosyllabic inputs Child's output Age Gloss

$\begin{array}{lll}\text { fos } & \text { pos } & 2 ; 2,20 \text { 'light', NOM.SG } \\ \text { bes } & \text { bes } & 2 ; 4,18 \text { 'come in', 2.IMP } \\ \text { xtes } & \text { tes } & 2 ; 9,13 \text { 'yesterday' } \\ \text { xtes } & \text { tes } & 2 ; 10,2 \text { 'yesterday' } \\ \text { Multisyllabic inputs } & \text { Child's output } & \\ \text { 'sakis } & \text { 'kakis } & 2 ; 2,28 \text { 'proper name', NOM } \\ \text { ba'bas } & \text { ba'bas } & 2 ; 2,21 \text { 'daddy', NOM.SG } \\ \text { 'markos } & \text { 'makos } & 2 ; 2,28 \text { 'proper name' NOM } \\ \text { 'tubes } & \text { 'pudes } & 2 ; 3,18 \text { 'somersault' NOM.PL } \\ \text { kur'tines } & \text { ti'tines } & 2 ; 5,23 \text { 'curtain', NOM.PL } \\ \text { kana'pes } & \text { pe'pes } & 2 ; 5,23 \text { 'couch', NOM.SG } \\ \text { kal'tson } & \text { to'ton } & 2 ; 3,18 \text { 'tights', NEUTR.NOM } \\ \text { bu'fan } & \text { bo'pan } & 2 ; 4,11 \text { 'anorak' NEUTR.NOM }\end{array}$

Within the Optimality framework, the realization of the final continuant consonant may be attributed to positional faithfulness (cf. Beckman, 1997) and this realization derives from the interaction of markedness and faithfulness constraints. The resistance of the final consonant to neutralization is attributed to constraints that licence features in a specific position, an interaction with a context-free markedness constraint. This licensing arises not from a featural alignment constraint, but rather from the position-sensitive faithfulness constraint IDENT-IO [cont $]_{\mathrm{Wd}-\text { fin }}$, that is relatively highly-ranked.

(66) IdENT-IO [cont $]_{\mathrm{Wd}-\mathrm{fin}}$ : An output segment standing in word final position has the same value for [continuant] as its input correspondence.

The IDENT-IO $[\text { cont }]_{\mathrm{Wd}-\text { fin }}$ is almost identical to the general faithfulness constraint IDENT-IO [cont], the only difference being that the later does not refer to word final position.

(67) Ident-Io [cont]: An output segment has the same value for [continuant] as its input correspondence. 
This pair of faithfulness constraints as in (66) and (67) is universally ranked such that the position-specific constraint is ranked above the general one, that is the context-free (cf. Pãnini's Theorem on constraint-ranking, given in Prince \& Smolensky, 1993)

(68) IDENT-Io $[\text { cont }]_{\mathrm{Wd}-\text { fin }}$ IDENT-Io [cont $]$

The above faithfulness constraints compete with the markedness constraint ${ }^{*}$ [cont], which prohibits continuant segments. The ranking in (69) expresses that [+continuant] segments will not surface except those that are licensed by a word final position (i.e. a word-final coda)

(69) Ident-IO $[\text { cont }]_{\mathrm{Wd}-\text { fin }}{ }^{*}[$ cont $]$ » IDENT-IO $[$ cont $]$

In (70) we reformulate the constraint ranking for STAGE II in the acquisition of codas.

(70) NoCoda » Ident-Io [cont $]_{\mathrm{Wd}-\text { fin }}{ }^{*}{ }^{*}$ cont $] »$ IDENT-Io [cont]

The constraint ranking in (70) evaluates only input forms with final coda, not with a medial one, which is still not allowed to surface due to the highly-ranked NoCodA. There follows an example with continuants word-initial and word-final.

(71) Adult form: $[\mathrm{xtes}] \rightarrow$ [tes $] \quad 2 ; 9,13 \quad$ 'yesterday'

\begin{tabular}{|c|c|c|c|c|c|}
\hline xtes & Complex & NoCodA & $\begin{array}{l}\text { IDENT-IO } \\
{[\text { cont }]_{W d-f i n}}\end{array}$ & ${ }^{*}[$ cont $]$ & $\begin{array}{c}\text { IDENT-IO } \\
\text { [cont }]\end{array}$ \\
\hline a. [xtes] & *! & * & $\checkmark$ & $*, *$ & $\checkmark$ \\
\hline b. [çes] & $\checkmark$ & * & $\checkmark$ & ${ }^{*},{ }^{*} !$ & $\checkmark$ \\
\hline c. $[$ tes] & $\checkmark$ & * & $\checkmark$ & * & $\checkmark$ \\
\hline
\end{tabular}

In the tableau $(71)$ the candidate (71a) violates the undominated ${ }^{\star}$ Complex constraint, therefore is excluded as an optimal output. Both candidates $(71 \mathrm{~b}, \mathrm{c})$, surfacing as single onsets, satisfy ${ }^{\star}$ CoMPLEx (cf. example 57); both candidates realize a final-coda segment $[\mathrm{s}]$, violating NoCodA, but satisfying IDENT-IO [cont $]_{\mathrm{Wd} \text {-fin }}$. The constraint ${ }^{*}$ [cont $]$ decides for the winning candidate. Candidate (71b) being a continuant violates the constraint and is ruled out. Candidate (71c) being a non-continuant satisfies ${ }^{\star}[$ cont $]$ and is selected as the optimal output, i.e. the effects of a low ranked constraint as ${ }^{\star}$ [cont] have consequences for the harmonic output, requiring that unmarked forms surface.

The occurrence of a coda-final segment may also be morphologically conditioned, since the fricative /s/ is the morphological marker of the gender/case for nouns or person in verbs. Forced by the morphological development, 
the realization of the coda-final segments can also be expressed as the promotion of the correspondence constraint ANCHORING-IO(GrWd, R), which blocks deletion at the right edge of a grammatical word. This later constraint dominates the NoCoDA constraint, blocks the deletion of the final input segment and in interaction with the IDENT-IO [cont $]_{\mathrm{Wd} \text {-fin }}$ constraint selects only a continuant as the optimal output. The results of constraints interaction are shown in (72) and an example is given in the tableau (73).

$$
\begin{aligned}
& \text { Anchoring-IO (GrWd, R) » NoCoda » Ident-io[cont] Wd-fin " } \\
& \text { * cont] » Ident-IO [cont] }
\end{aligned}
$$

\begin{tabular}{|c|c|c|c|c|c|}
\hline 'markos & $\begin{array}{l}\text { ANCHOR- } \\
\text { (GrWd, R) }\end{array}$ & NoCodA & $\begin{array}{l}\text { IDENT-IO } \\
{[\text { cont }]_{W d-f i n}}\end{array}$ & ${ }^{*}[$ cont $]$ & $\begin{array}{c}\text { IDENT-IO } \\
\text { [cont] }\end{array}$ \\
\hline a. [mar.kos] & $\checkmark$ & $* *$ & $\checkmark$ & * & $\checkmark$ \\
\hline b. [ma.ko] & * & $\checkmark$ & & $\checkmark$ & \\
\hline c. $[$ ma.kos] & $\checkmark$ & * & $\checkmark$ & * & $\checkmark$ \\
\hline d. [ma.kot] & $\checkmark$ & * & $* !$ & $\checkmark$ & * \\
\hline
\end{tabular}

(73) Adult form: ['markos] $\rightarrow$ ['makos] 2;2,28 'proper name', NOM

The constraints FtBin and $\operatorname{Max}(\mathrm{I}-\mathrm{O})$ are not included in the above tableau (73) because in this case they do not play a role in the selection of the optimal candidate. $\operatorname{Max}(\mathrm{I}-\mathrm{O})$ is low-ranked, dominated by NoCoDA, so that no medial codas may surface. The candidate (73a) being faithful to the input satisfies the dominating ANCHOR-IO $(\mathrm{GrWd}, \mathrm{R})$ constraint, but has a double violation of the NoCodA constraint; one violation for the realization of the medial coda segment $[\mathrm{r}]$ and one violation for the final coda $[\mathrm{s}]$, therefore it is ruled out. The codaless candidate ( $73 \mathrm{~b}$ ) violates the highly ranked ANCHOR-IO (GrWd, R) constraint, because the right edge of the candidate does not correspond with the right edge of the input grammatical word in Nominative Sg., therefore is excluded as an optimal output, although it surfaces as an unmarked (codaless) syllable. The candidates (73c) and (73d) satisfy the dominating ANCHOR$\mathrm{IO}(\mathrm{GrWd}, \mathrm{R})$ constraint, because the outputs have a coda-final segment as the input does. Both candidates have only one violation of NoCoda constraint, because of the realization of a coda-final segment, i.e. both violate the NoCoDA constraint minimally. (The deletion of the medial coda $[r]$ violates only the lower ranked $\operatorname{Max}(\mathrm{I}-\mathrm{O})$ and is irrelevant). The satisfaction or violation of IDENT-IO $[\text { cont }]_{\text {Wd-fin }}$ constraint makes the decision for the winning candidate. Candidate (73d) being a non-continuant $[t]$ violates the constraint and is ruled out. Candidate $(73 \mathrm{c})$ being a continuant $[\mathrm{s}]$ satisfies the constraint IDENTIo[cont $]_{\mathrm{Wd}-\text { fin }}$ and is selected as the optimal output. 
Although the segment /s/ surfaces as coda in word final position, it is still realized as a stop in all other contexts (cf. Section 3.1), i.e. prevocalic, in wordinitial or medial position, either via consonant harmony (74a) or by default (74b,c) (cf. Kappa, 2001). In the first studies on the acquisition of Greek, Drachman (1978:128) calls this consonant harmony 'prophylactic' and he points out that it may be used strategically, where a consonant would otherwise be completely lost. ${ }^{30}$

$\begin{array}{llllll} & & \text { Input } & \text { Child's output } & \text { Age } & \text { Gloss } \\ \text { a. Word-initial: } & \text { ['siko] } & \text { ['ciko] } & 2 ; 2,28 & \text { 'get up', 2.IMP } \\ \text { b. } & & \text { ['sula] } & \text { ['tula] } & 2 ; 3,18 & \text { 'proper name', FEM } \\ \text { c. } & \text { Word-medial: } & \text { ['piso] } & \text { [pito] } & 2 ; 2,20 & \text { 'back' }\end{array}$

Within the Optimality framework, the realization of the final continuant consonant derives from the interaction of markedness NoCoda constraint, with the correspondence constraint Anchoring-IO(GrWd, R) and the faithfulness constraint IDENT-IO[cont $]_{\mathrm{Wd} \text {-fin }}$. The preservation of final segment is attributed to ANCHORING-IO(GrWd, R) constraint that 'anchors' features in a specific position of the grammatical word, in this case word final, while the action of highly-ranked faithfulness constraint IDENT-IO[cont $]_{\text {Wd-fin }}$ obtains that the final segment will be a continuant. The failure of fricative /s/ (or any fricative) to surface syllable initially or medially is attributed to the action of the ${ }^{\star}[$ cont. $]$ constraint.

(75) Adult form: ['sakis] $\rightarrow$ ['kakis] 2;2,28 'proper name', NOM

\begin{tabular}{|c|c|c|c|c|c|}
\hline 'sakis & $\begin{array}{l}\text { ANCHOR- } \\
\text { (GrWd, R) }\end{array}$ & NoCoda & $\begin{array}{l}\text { IDENT-IO } \\
{[\text { cont }]_{W d-f i n}}\end{array}$ & $*[$ cont $]$ & $\begin{array}{c}\text { IDENT-IO } \\
\text { [cont] }\end{array}$ \\
\hline a. ['sakis] & $\checkmark$ & * & $\checkmark$ & $* * !$ & $\checkmark$ \\
\hline b. ['saki] & * & $\checkmark$ & & * & $\checkmark$ \\
\hline c. ['kaki] & * & $\checkmark$ & & $\checkmark$ & * \\
\hline d. ['kakis] & $\checkmark$ & * & $\checkmark$ & * & * \\
\hline
\end{tabular}

The above candidates $(75 \mathrm{~b}, \mathrm{c})$ may not be the optimal outputs at this stage of development, because both violate the undominated ANCHORING-IO(GrWd, R) constraint. The right edge of each candidate does not correspond with the right edge of the input grammatical word. Therefore both candidates are eliminated. The really competing candidates are (75a) and (75d). Both satisfy the undominated Anchoring-IO(GrWd, R) and the IDEnT-Io[cont $]_{\mathrm{Wd}-\text { fin }}$ both 
violate the high ranked NoCoda constraint. Although both violate the markedness ${ }^{\star}$ [cont] constraint, candidate $(75 \mathrm{~d})$ is selected as optimal since it violates

* [cont] minimally. It has only one violation, while its contestant (75a) incurs two violations (cf. Kappa 2001, for the application of consonant harmony).

The above data support also claims made by other researchers (e.g. for English, Ferguson 1978; Dinnsen 1996; Edwards 1996), that the word final position is 'favoured' for fricatives, namely the fricatives are acquired earlier in final position, and there is a clear tendency for substitutes of tighter closure, i.e. stops, to predominate in word initial position.

\section{Conclusions}

This paper discusses the acquisition of syllabic structure by a Greek child. It has been shown that the child's phonology reflects properties of Universal Grammar. At the early stages the child produces only unmarked CV-syllables with initial stops, nasals and laterals and her phonology shows no contrast for the feature [continuant], i.e. for obstruents only the unmarked [-continuant] feature is realized until the age of 2;6. The child's grammar has no complex onsets until late in the phonological development therefore all complex (target) clusters are reduced to the less sonorous or to the less marked segment. The reduction to the less sonorous segment is blocked due to the action of OCP, if within the word there is another consonant bearing the same place of articulation with the less sonorous segment, and results in a reduction to the more sonorous segment. The paper provides evidence that the fricatives are acquired earlier in word-final position than in word-medial position and later in wordinitial position.

\section{Notes}

* I would like to thank the editors of Journal of Greek Linguistics for giving me the opportunity to present this article and I am grateful to Prof. Gaberell Drachman for his help. I would also like to thank the anonymous reviewers for their most helpful comments. All errors remain my own.

1. Kappa (2001) provides also evidence, that the minimal prosodic word, i.e. trochaic foot, constitutes the harmonic domain for the application of consonant harmony $(\mathrm{CH})$ in child Greek $\mathrm{CH}$ involves the alignment of labial and dorsal place features with the left edge of the trochaic foot in which a particular feature is favoured to occur in particular position. 
2. Fikkert's analysis uses a prosodically based 'minimal word' template that imposes a single foot limit.

3. The study of Malikouti-Drachman (1999) discusses two types of hypocoristic formation of proper nouns in Standard Greek, i.e. hypocoristics formed by reduplication and those formed by truncation. As pointed out by an anonymous reviewer there are important differences to be noted in the effects of given constraints, as between acquisition and adult language. Thus the constraint ${ }^{*}$ CONTINUANT in acquisition becomes reduced, in reduplicated hypocoristics, to STRONG-ONSET (Segment prominence is seen as strength for stops and noncoronal spirants).

4. At this point OT has a closer affinity to Natural Phonology (Stampe 1973) than to SPE (Chomsky \& Halle 1968). OT is focused on the interactional properties of simple universal constraints through language-specific ranking. Likewise, Natural Phonology recognizes a set of universal processes that can be suppressed on a language-specific basis. SPE is focused on the formal properties of language-specific rules, developing a set of notational conventions that encode claims about which phonologies are less likely.

5. Generally, markedness refers to the complexity of a given structure relative to another structure, as determined by, for example, language typologies, frequency of occurrence and order of acquisition facts (cf. Greenberg 1965; Jakobson 1968, among others). Unmarked properties of language are those structures that are considered to be most basic because they are present in all grammars.

6. Stampe (1969) claims that child and adult phonology are subject to same set of natural processes. A phonetic change results when processes are not correctly limited, suppressed or ordered during acquisition and this phonetic change is responsible for much of historical sound change. Drachman (1978:124f) challenges Stampe's claim and points to disparities between child and adult phonology, i.e. processes found in early child language (e.g. consonant harmony) are not attested in adult languages or other types of very common processes of early child language are at important points non-overlap with those of adult language and language change, as regards, either frequency of occurrence, function and motivation or subtypes.

7. For further discussion of the differences between OT and Natural Phonology, see McCarthy (2002:51). For constraint ranking in OT and process suppression or limitation in Natural Phonology, see Pater (1997:234).

8. Cf. Drachman (1973b, 1975, 1978). Developmental strategies: (a) The strategy of avoidance, i.e. systematic avoidance of forms (also deletion of segments) presenting especially intractable production problems; (b) Adoption of some alternative production mechanism which provides a closer acoustical match for a given segment of the target language than the child's own best 'proper' effort could produce; (c) Exploitation of a special kind of context-sensitivity, that producing vowel and consonant harmony across syllables.

9. See Menn \& Matthei (1992) for a review of such dual-lexicon approaches.

10. For further discussion and arguments on the status of voiced plosives in Modern Greek, see, Malikouti (1970), Joseph \& Philippaki-Warburton (1986), Pagoni (1993), Kappa (1995), Holton et al. (1997), Arvaniti \& Joseph (2000), among others. 
11. For a discussion on the status of affricates in Modern Greek, see Kappa (1995) and references therein.

12. See Malikouti (1970), Kappa (2002), among others, for a discussion on the status and distribution of [j], viz. as a palatal allophone of $/ \mathrm{\gamma} /$ or as a segments derived from the vowel $/ \mathrm{i} /$.

13. An analysis of the syllable-structure, syllabification etc. of (adult) Greek is beyond the scope of this paper (for a discussion and analysis, see Malikouti-Drachman 1984; Pagoni 1993; Kappa 1995, among others).

14. The tautosyllabic 2-member onsets in Modern Greek have a minimal sonority distance $\geq 4$ between their members, where the feature [voice] is the primary parameter on the sonority scale (cf. Malikouti-Drachman 1984).

15. The Obligatory Contour Principle (OCP) prohibits the occurrence of identical feature specifications (for manner/place of articulation etc.) on adjacent segments (cf. McCarthy 1986; Yip 1988 among others).

16. The clusters $[\mathrm{pt}]$ and $[\mathrm{kt}]$ have respectively the variants $[\mathrm{ft}]$ and $[\mathrm{xt}]$ in the vocabulary of demotic (spoken) Greek, e.g. [fte'ro] 'wing', [xti'po] 'I hit'.

17. The voiceless clusters $[\mathrm{s} \theta, \mathrm{sx}, \mathrm{x} \theta, \mathrm{f} \theta]$ may have respectively the variants [st, sk, $\mathrm{xt}, \mathrm{ft}]$ in the vocabulary of demotic Greek or in dialects, e.g. ['stenos] 'strength', [ske'ðon] 'almost', [xtes] 'yesterday, [fti'no] 'cheap'. These (demotic) clusters obey the constraint OCP $_{\text {MANNER }}$, which requires that the two members of a voiceless obstruent cluster must be dissimilar in manner of articulation. The choice between the two alternative forms depends on the degree of formality or the register, in a given discourse, or even individual preferences. Thus words with clusters of fricatives or plosives are more formal than their corresponding dissimilated variants (Holton et al. 1997).

18. One of the reviewers mentioned the cluster [zbr-] as well. This cluster is attested in north dialects as a variant of [spr-], e.g. ['zbroxno] 'I push' (['sproxno] in standard Greek).

19. Joseph \& Philippaki-Warburton (1986) give a maximal final sequence consisting of three consonants in an (admittedly foreign) word such as tanks 'tank'.

20. In the adult language, synchronically or in diachronic change, occurs the opposite process, i.e. a stop is produced as a fricative. This happens because the adult has mastered his vocal tract and s/he "allows" a less extreme gesture to replace stop with a fricative in order to achieve what is "easiest” (Drachman 1978:125).

21. The $\operatorname{Max}(\mathrm{I}-\mathrm{O})$ and $\operatorname{Dep}(\mathrm{I}-\mathrm{O})$ constraints (earlier Parse and Fill) belong to the Correspondence theory, which expands on the notion of faithfulness used by Prince \& Smolensky (1993).

22. Cf. Grijzenhout \& Joppen (1998) for the function of ${ }_{\text {word }}{ }^{\star}[$ cont $]$ in German.

23. Cf. Pater (1997) on minimal violation of constraints in the phonological development.

24. Kappa (1999) proposed that in Sofias phonology the Labials are highly ranked, dominating Dorsals and Coronals (Place hierarchy: Labial » Dorsal » Coronal). This ranking is based on the fact that Labials do not undergo harmony, while Dorsals and Coronals do. Kiparsky (1994) proposes a universal hierarchy Labial, Dorsal » Coronal. 
25. Work supported by historical and dialectal data shows that in (adult) Greek a different place hierarchy obtains, i.e. Coronal » Dorsal» Labial (cf. Malikouti-Drachman 2001). This ranking is based on the fact that for the syllabification of obstruent clusters, the relative hierarchical strength of different places of articulation must also be taken into account in relation to the constraints Strong Onset and Weak Coda. Thus, the coronal segment of an obstruent cluster are syllabified as (strong) onset and the dorsal or labial segment as (weak) coda, or the dorsals as onsets and the labials as codas.

26. Cited in Barlow \& Dinnsen (1998).

27. OCP effects on labial are common in adult languages (Yip 1988).

28. Cf. Gnanadesikan (1996) for similar results on the function of OCP in cases of coalescence.

29. There is also evidence that in the early stages codas are permitted. Therefore some children begin language acquisition with a low ranking of ${ }^{\star}$ NoCoDA, fairly adult like (cf. Stemberger, 1996, in a study of an English-speaking child whose first word was [/ap ${ }^{\mathrm{h}}$ ] 'up' at the age of $0 ; 11$. At no stage of development did this child ever delete a word-final coda). In a study on the very early acquisitional stages of a German-speaking child, Grijzenhout \& Joppen (1998) show that although the final consonant(s) are reduced in the CVC, CV:C or CVCC structures, codas are always realized if the target (monosyllabic) forms do not have a word-initial consonant, e. g. [an] 'at' at the ages of 1;2-1;4,26. Grijzenhout \& Joppen argue that each output word has to show a maximal contrast between a consonant and a vowel in either order.

30. Drachman (1975) points out, that there is a period of such 'long-domain processes', whose 'ontogeny' is held to lie in the developing speech-tract control system. This 'period varies from child to child and during the course of maturation of articulatory abilities continues on its parallel way'. Drachman (1978:127) points out, that, for the child, the inertial or anticipatory repetition of gesture constitutes 'one kind of output-programming economy'.

\section{References}

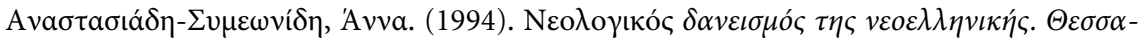

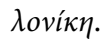

Arvaniti, Amalia \& Brian D. Joseph. 2000. "Variation in Voiced Stop Prenasalization in

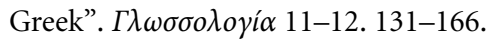

Barlow, Jessica A. 1997. A Constraint-Based Account of Syllable Onsets: Evidence from Developing Systems. Ph.D. dissertation, Indiana University, Bloomington.

Barlow, Jessica A. \& Daniel A. Dinnsen. 1998. "Asymmetrical Cluster Development in a Disordered System”. Language Acquisition 7. 1-49.

Beckman, Jill. 1997. "Positional Faithfulness, Positional Neutralisation and Shona Vowel Harmony”. Phonology 14. 1-46.

Bernhardt, Barbara, John Gilbert \& David Ingram, eds. 1996. Proceedings of the UBC, International Conference on Phonological Acquisition. Somerville, MA: Cascadilla Press. 
Bernhardt, Barbara \& Joseph P. Stemberger. 1998. Handbook of Phonological Development. San Diego: Academic Press.

Chin, Stephen B. \& Daniel A. Dinnsen. 1992. "Consonant Clusters in Disordered Speech: Constraints and Correspondence Patterns". Journal of Child Language 19. 259-285.

Chomsky, Noam \& Morris Halle. 1968. The Sound Pattern of English. New York: Harper and Row.

Clements, Nick G. 1990. "The Role of Sonority Cycle in Core Syllabification". Papers in Laboratory Phonology I: Between the Grammar and Psysics of Speech, ed. by John Kingston \& Mary Beckman, 283-333. New York: Cambridge University Press.

Demuth, Katherine. 1995. "Markedness and the Development of Prosodic Structure". Proceedings of NELS 25, vol. 2: Papers from the Workshops on Language Acquisition and Language Change, ed. by Jill Beckman, 13-25. Amherst: GLSA.

Demuth, Katherine. 1997. "Multiple Optimal Outputs in Acquisition". University of Maryland Working Papers in Lingusitics, vol. 5, ed. by Viola Miglio \& Bruce Morén. 53-71.

Dinnsen, Daniel. 1996. "Context-sensitive Underspecification and the Acquisition of Phonemic Contrasts". Journal of Child Language 23. 57-79.

Drachman, Gaberell. 1973a. "Baby Talk in Greek". Ohio State University Working Papers in Linguistics 15, ed. by Angeliki Malikouti-Drachman, Gaberell Drachman, Mary Louise Edwards, Jonny E. Geis and Lawrence C. Schourup, 174-189. Columbus, Ohio.

Drachman, Gaberell. 1973b. "Some Strategies in the Acquisition of Phonology". Issues in Phonological Theory, ed. by Michael Kenstowicz and Charles Kisseberth, 145-159. The Hague: Mouton.

Drachman, Gaberell. 1975. “Generative Phonology and Child Language Acquisition”. Phonologica 1972, ed. by Wolfgang U. Dressler and F. B. Mareš, 235-251. München: Fink.

Drachman, Gaberell. 1978. "Child language and language change: a conjecture and some refutations". Recent Developments in Historical Phonology, ed. by Jacek Fisiak, 123-144. The Hague: Mouton.

Drachman, Gaberell. \& Angeliki Malikouti-Drachman. 1997. "Dissimilation in Cypriot Greek: competing analyses". Studies in Greek Linguistics 17, 57-71. Univ. of Thessaloniki: Thessaloniki

Edwards, Mary Louise. 1996. "Word Position Effects in the Production of Fricatives", ed. by Barbara Bernhardt, John Gilbert \& David Ingram, 149-158.

Fee, Jane. 1992. "Exploring the Minimal Word in Early Phonological Acquisition". Proceedings of the 1992 Annual Conference of the Canadian Linguistic Association. Toronto: Toronto Working Papers in Linguistics.

Fee, Jane. 1995. "Segments and Syllables in Early Language Acquisition”. Phonological Acquisition and Phonological Theory, ed. by John Archibald, 43-61. Hillsdale, NJ: Erlbaum.

Fee, Jane. 1996. "Syllable Structure and Minimal Words", ed. by Barbara Bernhardt, John Gilbert \& David Ingram, 85-98

Ferguson, Charles A. 1978. "Fricatives in Child Language Acquisition". Papers on Linguistics and Child Language, ed. by. Honsa V. \& M.J. Hardman-de Bautista, 93-115. The Hague: Mouton.

Fikkert, Paula. 1994. On the Acquisition of Prosodic Structure. Dordrecht: HIL Dissertations No. 6. 
Gnanadesikan, Amalia. 1996. "Child Phonology in Optimality Theory: Ranking Markedness and Faithfulness Constraints". Proceedings of the 20th annual Boston University Conference on Language Development, ed. by Stringfellow, Andy, Dalia Cahana-Amitay, Elizabeth Hughes \& Andrea Zukowski, 237-248. Sommerville, MA: Cascadilla Press.

Goad, Heather. 1998. "On the Status of Final Consonants in Early Child Language". Proceedings of the 22th annual Boston University Conference on Language Development, ed. by Greenhill Annabel, Mary Hughes, Heather Littlefield \& Hugh Walsh, 269-280. Sommerville, MA: Cascadilla Press.

Greenberg, Joseph. 1965. "Some Generalizations concerning Initial and Final Consonant Sequences”. Linguistics 18. 5-34.

Greenlee, M. 1974. "Interacting Processes in the Child's Acquisition of Stop-Liquid Clusters". Papers and Reports on Child Language Development 7. 85-100.

Grijzenhout, Janet \& Sandra Joppen. 1998. First Steps in the Acquisition of German Phonology. Ms. Paper presented at the 3rd Utrecht Biannual Phonology Workshop. Utrecht Institute of Linguistics OTS (also in RoA\#400 [http://roa.rutgers.edu]).

Hale, Mark \& Charles Reiss. 1996. The Initial Ranking of Faithfulness Constraints in UG. Ms. Concordia University (also in RoA\#104 [http://roa.rutgers.edu]).

Hale, Mark \& Charles Reiss. 1998. "Formal and Empirical Arguments concerning Phonological Acquisition”. Linguistic Inquiry 29. 656-683.

Holton, David, Mackridge Peter \& Philippaki-Warburton Irene. 1997. Greek. A Comprehensive Grammar of the Modern Language. London: Routledge.

Itô, Junko. 1986. Syllable Theory in Prosodic Phonology. Ph.D. dissertation, University of Massachusetts. Amherst.

Joseph Brian.D. \& Irene Philippaki-Warburton. 1986. Modern Greek. London: Croom Helm. Jakobson, Roman. 1968. Child Language, Aphasia and Phonological Universals. The Hague \& Paris: Mouton.

Kappa Ioanna. 1995. Silbenphonologie im Deutschen und Neugriechischen. Ph.D. dissertation, University of Salzburg.

Kappa, Ioanna. 1998a. "The Realisation of Affricates in Child Language". Proceedings of the 12th International Symposium on Theoretical and Applied Linguistics, ed. by Stella Lambropoulou, 322-330. University of Thessaloniki: Thessaloniki.

Kappa, Ioanna. 1998b. On the Acquisition of Prosodic Structure: Evidence from Modern Greek. Ms. Paper presented at the 3rd Utrecht Biannual Phonology Workshop. Utrecht Institute of Linguistics OTS

Kappa, Ioanna. 1999. "Developmental Patterns in the Acquisition of Onsets in Modern Greek”. Greek Linguistics '97, ed. by Amalia Moser, 799-807. Athens: Ellinika Grammata. Kappa Ioanna. 2000. "On the Acquisition of Fricatives". Proceedings of the 13th International Symposium on Theoretical and Applied Linguistics. Festschrift for Prof. Athanasios Kakuriotis, ed. by Katerina Nicolaidis \& Maria Mattheoudaki, 197-205. University of Thessaloniki: Thessaloniki.

Kappa Ioanna. 2001. "Alignment and Consonant Harmony: Evidence from Greek". Proceedings of the 25th Boston University Conference on Language Development, ed. by Anna H-J. Do, Laura Domínguez \& Aimee Johansen, 401-412. Sommerville, MA.: Cascadilla Press. 
Kappa Ioanna. 2002. "Final Coda Licensing in Greek". Proceedings of the GALA 2001 Conference on Language Acquisition, ed. by João Costa \& Maria João Freitas, 320-326. Lisboa:Associação Portuguesa de Linguistica.

Kappa Ioanna. 2002. "Morphophonemische Alternationen und der Status von [j] im Griechischen". Sprachwissenschaft auf dem Weg in das dritte Jahrtausend, ed. by Reinhard Rapp, 757-763. Frankfurt/Main:Peter Lang.

Kappa Ioanna. To appear. "On the Phonological Development of the early Words: a Case Study". Proceedings of the 14th International Symposium on Theoretical and Applied Linguistic, ed. by Marianthi Makri-Tsilipakou. Thessaloniki:University of Thessaloniki. Kiparsky, Paul \& Lise Menn. 1977. "On the Acquisition of Phonology". Language and Thought, ed. by John MacNamara, 47-78. New York: Academic Press.

Kiparsky, Paul. 1994. Remarks on Markedness. Paper presented at TREND 2.

Lleó, Conxita \& Michael Prinz. 1996. "Consonant Clusters in Child Phonology and the

Directionality of Syllable Structure Assignment”. Journal of Child Language 23. 31-56.

Lohuis-Weber, Heleen \& Wim Zonneveld. 1996. "Phonological Acquisition and Dutch Word Prosody". Language Acquisition 5. 245-283.

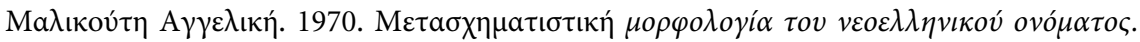

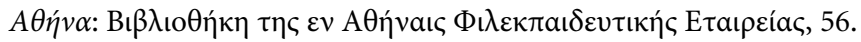

Malikouti-Drachman Angeliki. 1984. "Syllables in Modern Greek”. Phonologica 1984, ed. by Wolfgang Dressler et al., 181-186. Cambridge: Cambridge University Press.

Malikouti-Drachman Angeliki. 1987. The Representation of Geminates in Greek" [in Greek]. Studies in Greek Linguistics 8. 275-291. Thessaloniki: Kiriakidi Bros.

Malikouti-Drachman Angeliki. 1999. “Constraints on Greek Hypocoristics”. Greek Linguistics '97, ed. by Amalia Moser, 391-399. Athens: Ellinika Grammata.

Malikouti-Drachman, Angeliki. 2001. "Syllable Constraints and Dialect Variation" [in Greek]. Studies in Greek Linguistics 21. 402-413. Thessaloniki: Kiriakidi Bros.

Malikouti-Drachman, Angeliki \& Gaberell Drachman. 1988. "Greek Clitics and Lexical Phonology”. Phonologica 1988, ed. by Wolfgang. U. Dressler. et al., 197-206. Cambridge: Cambridge University Press.

Malikouti-Drachman, Angeliki \& Gaberell Drachman. 1989. "Stress in Modern Greek” [in Greek]. Studies in Greek Linguistics 9. 127-143. Thessaloniki: Kiriakidi Bros.

McCarthy, John. 1986. “OCP Effects: Gemination and Antigemination”. Linguistic Inquiry 17. 207-264.

McCarthy, John. 2002. A Thematic Guide to Optimality Theory. Cambridge: Cambridge University Press.

McCarthy, John \& Alan Prince. 1994. "The Emergence of the Unmarked: Optimality in Prosodic Morphology”. NELS 24, ed. by Mercè Gonzàlez. 333-379. Amherst, MA: GLSA. McCarthy, John \& Alan Prince. 1995. "Faithfulness and Reduplicative Identity". Papers in Optimality Theory 18, ed. by Jill N. Beckman, Laura W. Dickey \& Suzanne Urbanczyk, 249-384. UMass, Amherst: GLSA.

Menn, Lise \& Edward Matthei. 1992. The 'Two-Lexicon' Account of Child Phonology. Phonological Development. Models, Research, Implications, ed. by Charles A. Ferguson, Lise Menn \& Carol Stoel-Gammon, 211-247. Timonium:York Press.

Ohala, Diane K. 1996. Cluster Reduction and Constraints in Acquisition. Ph. D. dissertation. University of Arizona. Tuscon. 
Pagoni Stamatia. 1993. Phonological Variation in Modern Greek: a Government Phonology Approach. Ph.D. dissertation. UCL. London.

Pater, Joe. 1997. "Minimal Violation and Phonological Development". Language Acquisition 6. 201-253.

Prince, Alan. 1980. “A Metrical Theory for Estonian Quantity”. Linguistic Inquiry 11. 511-562.

Prince, Alan \& Paul Smolensky. 1993. Optimality Theory:Constraint Interaction in Generative Grammar. Ms, Rutgers University \& University of Colorado, Boulder.

Smolensky, Paul. 1996. "On the Comprehension/Production Dilemma in Child Language". Linguistic Inquiry 27. 720-731.

Stampe, David. 1969. "The Acquisition of Phonetic Representation". Papers from the Fifth Regional Meeting, Chicago Linguistic Society. 443-454.

Stampe, David. 1973. A Dissertation on Natural Phonology. Ph.D. Dissertation, University of Chicago.

Stemberger, Joseph, P. 1996. "Syllable Structure in English, with Emphasis on Coda”, ed. by Bernhardt, Barbara, John Gilbert \& David Ingram, 62-75.

Tesar, Bruce \& Paul Smolensky. 1998. "Lernability of Optimality Theory". Linguistic Inquiry 29. 229-268.

Tesar, Bruce \& Paul Smolensky. 2000. Lernability in Optimality Theory. Cambridge, MA: MIT Press.

Tzakosta, Marina. 2001. "The Realization of Consonant Clusters in Child Language” [in Greek]. Studies in Greek Linguistics 21, 736-746. Thessaloniki: Kiriakidi Bros.

Tzakosta, Marina. To appear. "Deletion and Insertion: Two Pathways towards Optimality". Proceedings of the 15th International Symposium on Theoretical and Applied Linguistics. University of Thessaloniki: Thessaloniki

Velleman, Shelley. 1996. "Metathesis Highlights Feature-by-Position Constraints", ed. by Bernhardt, Barbara, John Gilbert \& David Ingram, 173-186.

Waterson, Natalie. 1971. “Child Phonology: a Prosodic View”. Journal of Linguistics 7. 179-211. Yip, Moira. 1988. "The Obligatory Contour Principle and Phonological Rules: A Loss of Identity”. Linguistic Inquiry 19. 65-100.

\section{$\Pi \varepsilon \rho i ́ \lambda \eta \psi \eta$}

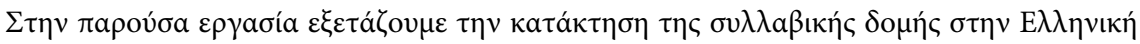

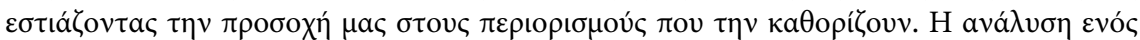

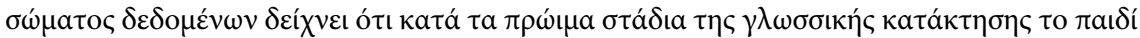

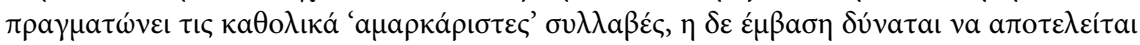

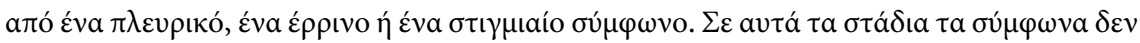

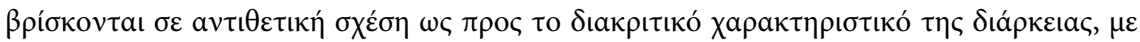

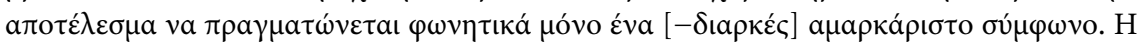

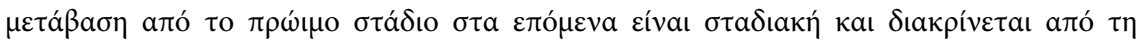

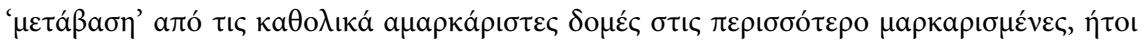

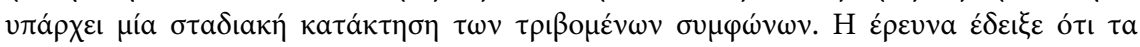




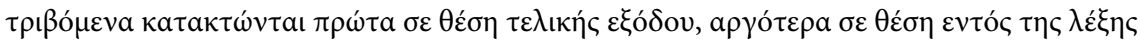

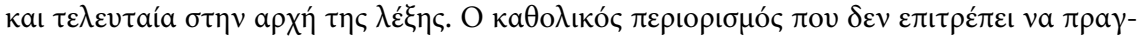

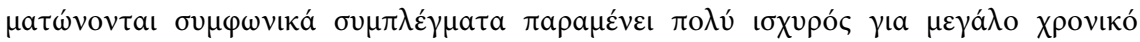

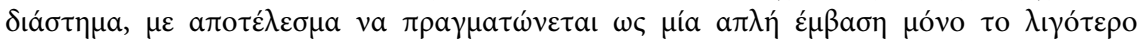

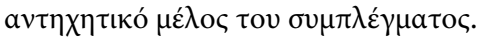

